\title{
Source apportionment of atmospheric water over East Asia - a source tracer study in CAM5.1
}

\author{
Chen Pan ${ }^{1,2,3,4}$, Bin Zhu ${ }^{1,2,3,4}$, Jinhui Gao ${ }^{1,2,3,4}$, and Hanqing Kang ${ }^{1,2,3,4}$ \\ ${ }^{1}$ Key Laboratory for Aerosol-Cloud-Precipitation of China Meteorological Administration, Nanjing University of Information \\ Science \& Technology, Nanjing, China \\ ${ }^{2}$ Collaborative Innovation Center on Forecast and Evaluation of Meteorological Disasters, Nanjing University of Information \\ Science \& Technology, Nanjing, China \\ ${ }^{3}$ Key Laboratory of Meteorological Disaster, Ministry of Education (KLME), Nanjing University of Information Science \& \\ Technology, Nanjing, China \\ ${ }^{4}$ Joint International Research Laboratory of Climate and Environment Change (ILCEC), Nanjing University of Information \\ Science \& Technology, Nanjing, China
}

Correspondence to: Bin Zhu (binzhu@ nuist.edu.cn)

Received: 29 September 2016 - Discussion started: 30 September 2016

Revised: 30 December 2016 - Accepted: 17 January 2017 - Published: 13 February 2017

\begin{abstract}
The atmospheric water tracer (AWT) method is implemented in the Community Atmosphere Model version 5.1 (CAM5.1) to quantitatively identify the contributions of various source regions to precipitation and water vapour over East Asia. Compared to other source apportionment methods, the AWT method was developed based on detailed physical parameterisations, and can therefore trace the behaviour of atmospheric water substances directly and exactly. According to the simulation, the northern Indian Ocean (NIO) is the dominant oceanic moisture source region for precipitation over the Yangtze River valley (YRV) and southern China (SCN) in summer, while the north-western Pacific (NWP) dominates during other seasons. Evaporation over the South China Sea (SCS) is responsible for only 2.7-3.7\% of summer precipitation over the YRV and SCN. In addition, the Indo-China Peninsula is an important terrestrial moisture source region (annual contribution of $\sim 10 \%$ ). The overall relative contribution of each source region to the water vapour amount is similar to the corresponding contribution to precipitation over the YRV and SCN. A case study for the SCS shows that only a small part $(\leq 5.5 \%)$ of water vapour originates from local evaporation, whereas much more water vapour is supplied by the NWP and NIO. In addition, because evaporation from the SCS represents only a small contribution to the water vapour over the YRV and SCN in summer, the SCS mainly acts as a water vapour transport pathway where moisture from the NIO and NWP meet.
\end{abstract}

\section{Introduction}

Water vapour is one of the most important components of the atmosphere, affecting global climate and weather patterns (Held and Soden, 2000). Among current studies of the hydrological cycle, the identification of moisture sources to the atmosphere is an important topic, because a better understanding of these sources will benefit long-term forecasting, disaster prevention, and allocation of water resources (Bosilovich and Schubert, 2002).

Source apportionment methods have been developed to identify atmospheric moisture source regions. These methods generally can be divided into three types, namely analytical models, isotopes, and numerical (Lagrangian and Eulerian) atmospheric water tracers (AWTs) (Gimeno et al., 2012). In addition, sensitivity experiments in numerical simulations, such as shutting down water vapour flux at the lateral boundaries or surface evaporation (Chow et al., 2008), are an approach to study the contributions of moisture from diverse regions. Analytical models, widely used in earlier studies (Brubaker et al., 1993; Burde and Zangvil, 2001; Eltahir and Bras, 1996; Savenije, 1995; Trenberth, 1999), are generally based on various simplifying assumptions such as a well-mixed atmosphere. The stable isotopes of water, $\mathrm{HDO}$ and $\mathrm{H}_{2}^{18} \mathrm{O}$, can be used to investigate the water cycle. However, water isotope data reflect a series of processes that occur simultaneously, which makes it difficult to interpret 
isotope results for the water cycle (Numaguti, 1999; Sodemann and Zubler, 2010). The Lagrangian method has become a popular way to analyse the transport of moisture and moisture sources of precipitation (Dirmeyer and Brubaker, 1999; Gustafsson et al., 2010; Sodemann et al., 2008; Stohl and James, 2004; Stohl et al., 2008). However, Gimeno et al. (2012) pointed out that the treatments of water vapour transport and changes of atmospheric water vapour in the Lagrangian method are not based on detailed physical equations. Sodemann and Zubler (2010) pointed out that a strong bias exists in Lagrangian precipitation estimates because all cloud processes are neglected. Sensitivity experiments generally contain non-linearities, which may lead to changes in the dynamic and thermodynamic structures of meteorological fields, suggesting that their results cannot be used to directly diagnose moisture sources. In contrast, the Eulerian AWT method has been developed based on detailed physical parameterisations in atmospheric models, enabling a direct and exact tracking of the behaviour of atmospheric water substances (Numaguti, 1999; Bosilovich, 2002).

The Eulerian AWT method was firstly developed by Joussaume et al. (1986) and Koster et al. (1986) for global circulation models (GCMs). Later, this AWT method was applied to diagnose regional water sources in GCMs. For example, Numaguti (1999) identified the moisture sources of Eurasian precipitation, and Bosilovich and Schubert (2002) diagnosed the moisture sources of precipitation over North America and India. Bosilovich et al. (2003) studied water sources of the large-scale North American monsoon, Bosilovich (2002) investigated the vertical distribution of water vapour tracers over North America, and Sodemann et al. (2009) used this method to study sources of water vapour leading to a flood event in central Europe using a mesoscale model. Finally, Knoche and Kunstmann (2013) incorporated the AWT method into a fifth-generation mesoscale model to study the transport of atmospheric moisture in western Africa.

In summer, the Asian summer monsoon (ASM) brings large amounts of water vapour to the East Asian (EA) continent, leading to a wet season and abundant precipitation. Simmonds et al. (1999) pointed out that the dominant moisture transport pathways during summer can be divided into three branches, namely (i) south-westerly flow associated with the Indian summer monsoon, (ii) southerly or south-easterly flow associated with the south-eastern Asian monsoon, and (iii) the mid-latitude Westerlies. Correspondingly, these pathways transport moisture from (i) the Bay of Bengal (BOB) and the Arabian Sea (AS), (ii) the South China Sea (SCS) and the north-western Pacific (NWP), and (iii) the mid-latitude regions. Simmonds et al. (1999) and $\mathrm{Xu}$ et al. (2008) pointed out that the BOB to SCS are the main source regions for rainfall over south-east China. Using the Lagrangian FLEXible PARTicle (FLEXPART) dispersion model (Stohl and James, 2004), Drumond et al. (2011) discovered that the inland regions of China receive moisture mostly from western Asia, whereas the East China Sea (ECS) and SCS are the main source regions for rainfall in China's eastern and south-eastern coastal areas, and the AS and BOB are the main source regions for southern and central China from April to September. With the FLEXPART model, Baker et al. (2015) demonstrated that the Indian Ocean is the primary source of moisture for East Asian summer monsoon (EASM) rainfall. Using the same model, Chen et al. (2013) suggested that the ECS, the SCS, the Indian peninsula and $\mathrm{BOB}$, and the AS were the four major moisture source regions for summer water vapour over the Yangtze River valley (YRV) during 2004-2009. Chow et al. (2008) suggested that water vapour supplied by the Indian summer monsoon contributed about $50 \%$ to early summer precipitation over China in 1998, and inferred that the SCS may act as a pathway for water vapour transport affected by the Indian and Southeast Asian summer monsoon. However, recently Wei et al. (2012), using a Lagrangian model, showed that the major moisture transport pathways to the YRV are over land and not over the ocean. Therefore, the dominant source regions of moisture for summer rainfall over EA are still uncertain.

Baker et al. (2015) pointed out that the water vapour transport mechanisms for precipitation over China during the ASM are still unquantified. Previous studies have pointed out that analytical models need simplifying assumptions, isotope data reflect more than just the water cycle, the Lagrangian methods lack cloud processes, and sensitivity experiments contain non-linearities, limiting diagnostic studies of moisture sources. On the other hand, the Eulerian AWT method does not have these shortcomings and is an accurate way to quantitatively determine water sources (Bosilovich, 2002). Therefore, in this study, we aim at incorporating an Eulerian AWT approach into an advanced global atmosphere model - the Community Atmosphere Model version 5.1 (CAM5.1) (Neale et al., 2012). Using this method, we address the following questions. (1) What moisture source regions are most important for precipitation and water vapour amounts over EA, including the YRV and southern China (SCN)? (2) What is the role of the SCS for precipitation and water vapour amount over EA during the EASM: a dominant source region or just a pathway for water vapour transport from other source regions?

In this study, detailed descriptions of physical parameterisation schemes and means of implementing the AWT mechanisms in CAM5.1 are given in Sect. 2. Simulation results, including evaluation and discussion, are presented in Sect. 3. Finally, summary and concluding remarks are presented in Sect. 4.

\section{Model and methods}

The CAM5.1, released by the US National Center for Atmospheric Research, is the atmospheric component of the Community Earth System Model (Neale et al., 2012). Compared to CAM4, CAM5.1 contains a range of improvements 


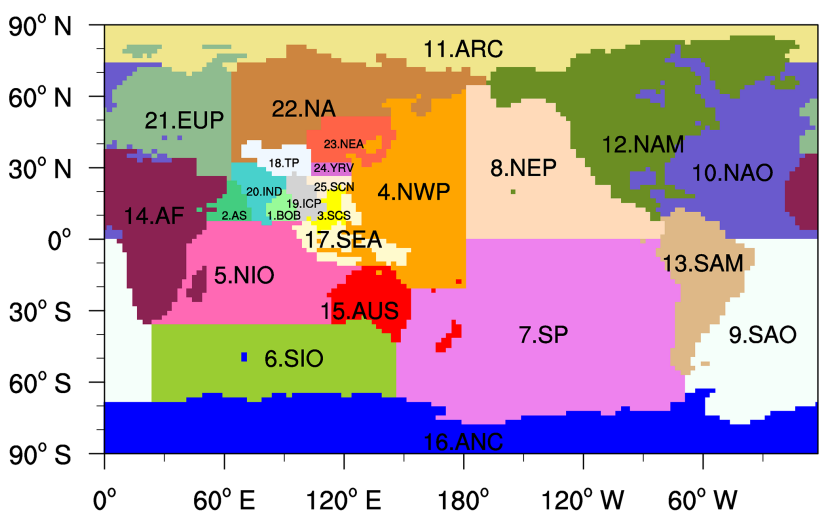

Figure 1. Moisture source regions: the regions are denoted as (1) Bay of Bengal: BOB; (2) Arabian Sea: AS; (3) South China Sea: SCS; (4) north-western Pacific: NWP; (5) northern Indian Ocean: NIO; (6) southern Indian Ocean: SIO; (7) southern Pacific: SP; (8) north-eastern Pacific: NEP; (9) southern Atlantic Ocean: SAO; (10) northern Atlantic Ocean: NAO; (11) Arctic Ocean: ARC; (12) North America: NAM; (13) South America: SAM; (14) Africa: AF; (15) Australia: AUS; (16) Antarctic: ANC; (17) Southeast Asia: SEA; (18) Tibet Plateau: TP; (19) Indo-China Peninsula: ICP; (20) India: IND; (21) Europe: EUP; (22) northern Asia: NA; (23) north-eastern Asia: NEA; (24) Yangtze River valley: YRV; (25) southern China: SCN.

in the representation of physical processes such as moist turbulence, shallow convection, stratiform microphysics, cloud macrophysics schemes, and others (Neale et al., 2012). The horizontal resolution used in this study is $1.9^{\circ}$ in latitude and $2.5^{\circ}$ in longitude. The vertical range is from the surface to approximately $4 \mathrm{hPa}(\approx 40 \mathrm{~km})$.

In this study, the chemistry mechanism of CAM5.1 is taken from MOZART-4 (Emmons et al., 2010), in which water vapour is invariant, which means that it is unnecessary to consider changes in water vapour during chemical processes. The basic simulations setup, including emissions and upper and lower boundary conditions, is identical to that of the specified dynamics simulations of CAM5 in Lamarque et al. (2012). In this study, the wet removal scheme in Horowitz et al. (2003) is adopted. The temporal evolution of the mass mixing ratios (MMRs) of different water substances (water vapour, cloud droplets, and ice) is determined by deep convection, shallow convection, cloud macrophysics, cloud microphysics, advection, and vertical diffusion. To diagnose the dominant moisture source regions of atmospheric water over EA, the global surface is divided into 25 source regions as shown in Fig. 1. Most regions are defined based on the locations of continents and oceans. Due to the focus on moisture sources over EA in this study, EA and its adjacent regions are further divided to provide more detail. Within source region $k$, the surface flux of the tagged water vapour tracer $E^{k}$ is equal to the surface evaporation flux of water vapour $E$; otherwise, $E^{k}=0$. As in the treatment described in Knoche and Kunstmann (2013) and Bosilovich and Schubert (2002), water is "tagged" when it evaporates at its source region and is no longer tagged when it precipitates from the atmosphere to the Earth's surface via atmospheric processes. When previously tagged precipitation reevaporates from the surface, it is regarded as newly tagged water (Knoche and Kunstmann, 2013), which then belongs to the region from where it reevaporates.

The MMRs of water vapour, cloud droplets, and ice at a particular level are defined as $q_{\mathrm{v}}, q_{\mathrm{l}}$, and $q_{\mathrm{i}}$, respectively. The corresponding MMRs of tagged water substances from source region $k$ are $q_{\mathrm{v}, \mathrm{tg}}^{k}, q_{1, \mathrm{tg}}^{k}$, and $q_{\mathrm{i}, \mathrm{tg}}^{k}$. We assume that all the tagged water substances from the source regions have the identical physical properties and are well-mixed. All these tagged water substances are passive, which means that they are entirely separate from the original water substances in CAM5.1 and have no impact on dynamical and thermal fields. Numaguti (1999) suggested that the lifetime of atmospheric water vapour is about 10 days. In this study, the simulation begins on 1 January 1997, and the initial MMRs of tagged substances are set to zero. To attain stable initial concentrations of tagged water substances, the simulation experiment takes a year to spin up. We then investigate the 10year-averaged results for 1998 to 2007 . In the following, we describe the treatment of tagged AWTs in CAM5.1's physical parameterisations.

\subsection{Deep convection}

In CAM5.1, deep convection is parameterised using the approach described in Zhang and McFarlane (1995), but with modifications following Richter and Rasch (2008) and Raymond and Blyth $(1986,1992)$. For the temporal evolution of $q_{\mathrm{v}, \mathrm{tg}}^{k}$, it is calculated in the same way as that of $q_{\mathrm{v}}$, but the relevant variables of tagged water vapour are substituted for the corresponding variables of original water vapour, expressed as

$$
\begin{array}{r}
\left(\frac{\partial q_{\mathrm{v}, \mathrm{tg}}^{k}}{\partial t}\right)_{\mathrm{dp}}= \\
\epsilon_{\mathrm{tg}}^{k}-c_{\mathrm{tg}}^{k}-\frac{1}{\rho} \frac{\partial}{\partial z}\left(M_{\mathrm{u}, \mathrm{dp}} q_{\mathrm{v}, \mathrm{u}, \mathrm{tg}}^{k}\right. \\
\left.+M_{\mathrm{d}, \mathrm{dp}} q_{\mathrm{v}, \mathrm{d}, \mathrm{tg}}^{k}-M_{\mathrm{c}, \mathrm{dp}} q_{\mathrm{v}, \mathrm{tg}}^{k}\right),
\end{array}
$$

where $M_{\mathrm{c}, \mathrm{dp}}$ is the net vertical mass flux, $M_{\mathrm{u}, \mathrm{dp}}$ is the upward mass flux, and $M_{\mathrm{d}, \mathrm{dp}}$ is the downward mass flux in the deep convection. $\epsilon_{\mathrm{tg}}^{k}$ and $c_{\mathrm{tg}}^{k}$ are the large-scale-mean evaporation and condensation rates of tagged water vapour, respectively. Here, $q_{\mathrm{v}, \mathrm{u}, \mathrm{tg}}^{k}$ and $q_{\mathrm{v}, \mathrm{d}, \mathrm{tg}}^{k}$ are the MMR of tagged water vapour in the updraft and that in the downdraft, respectively. The ratio between the MMR of tagged water vapour and the corresponding sum is used to calculate the condensation rate $c_{\mathrm{tg}}^{k}$ :

$c_{\mathrm{tg}}^{k}=\left(\frac{q_{\mathrm{v}, \mathrm{tg}}^{k}}{\sum_{k=1}^{n} q_{\mathrm{v}, \mathrm{tg}}^{k}}\right) c$, 
where $c$ is the condensation of original water vapour. In this study, $n=25$, which is the total number of defined source regions (Fig. 1). In this scheme, the tagged cloud water in the updraft, the detrainment of tagged cloud water, rain production rate, and the evaporation rate of tagged rain in the downdraft are calculated in the same manner as that for the corresponding quantities for original water. However, the relevant variables of tagged water vapour are substituted for the corresponding variables of original water vapour. Detailed formulas for relevant quantities for original water in the updraft and downdraft are presented in Sect. 3 of Zhang and McFarlane (1995). The evaporation of convection precipitation is also considered in this parameterisation. The evaporation rate $\left(\frac{\partial q_{\mathrm{v}}^{k}}{\partial t}\right)_{\mathrm{dp} \_ \text {evap }}$ at level $m$ is associated with the deep convection precipitation flux $\left(Q_{m}\right)_{\mathrm{dp}}$ at the top interface of this level (Sundqvist, 1998), expressed as

$$
\left(\frac{\partial q_{\mathrm{v}}^{k}}{\partial t}\right)_{\mathrm{dp} \_ \text {evap }}=k_{e}\left(1-\mathrm{RH}_{m}\right) \sqrt{\left(Q_{m}\right)_{\mathrm{dp}}},
$$

where $\mathrm{RH}_{m}$ is the relative humidity at level $m$ and the coefficient $k_{e}=2 \times 10^{-6}\left(\mathrm{~kg} \mathrm{~m}^{-2} \mathrm{~s}^{-1}\right)^{-1 / 2} \mathrm{~s}^{-1}$. The individual evaporation rate of tagged convection precipitation from source region $k$ is calculated as

$$
\begin{aligned}
& \left(\frac{\partial q_{\mathrm{v}, \mathrm{tg}}^{k}}{\partial t}\right)_{\mathrm{dp} \_ \text {evap }}= \\
& \begin{cases}k_{e}\left(1-\mathrm{RH}_{m}\right) \frac{\left(Q_{m, \mathrm{tg}}^{k}\right)_{\mathrm{dp}}}{\sqrt{\sum_{k=1}^{n}\left(Q_{m, \mathrm{tg}}^{k}\right)_{\mathrm{dp}}}}, & \text { if } \sum_{k=1}^{n}\left(Q_{m, \mathrm{tg}}^{k}\right)_{\mathrm{dp}} \neq 0, \\
0, & \text { if } \sum_{k=1}^{n}\left(Q_{m, \mathrm{tg}}^{k}\right)_{\mathrm{dp}}=0\end{cases}
\end{aligned}
$$

In general, the evaporation rate of convection precipitation is very small compared to the tendency of water vapour in the deep convection (Neale et al., 2012). For the temporal evolution of $q_{1, \mathrm{tg}}^{k}$ and $q_{\mathrm{i}, \mathrm{tg}}^{k}$ in the deep convection parameterisation, both are treated in the same subroutine as $q_{1}$ and $q_{\mathrm{i}}$.

\subsection{Shallow convection}

The shallow convection scheme in CAM5.1 is taken from Park and Bretherton (2009). Similar to the MMR of the total water $q_{\mathrm{t}}$, the MMR of the tagged total water $q_{\mathrm{t}, \mathrm{tg}}^{k}$ is also assumed to be a conserved quantity in non-precipitating moist adiabatic processes. In this scheme, the diagnostic equations for the shallow convective mass flux $M_{\mathrm{u}, \mathrm{sh}}$ and the MMR of the updraft total water $q_{\mathrm{t}, \mathrm{u}}$ (Bretherton et al., 2004) are expressed as

$$
\frac{\partial M_{\mathrm{u}, \mathrm{sh}}}{\partial z}=E_{\mathrm{tr}}-D_{\mathrm{tr}}
$$

and

$$
\frac{\partial}{\partial z}\left(q_{\mathrm{t}, \mathrm{u}} M_{\mathrm{u}, \mathrm{sh}}\right)=E_{\mathrm{tr}} \bar{q}_{\mathrm{t}}-D_{\mathrm{tr}} q_{\mathrm{t}, \mathrm{u}}+\left(\frac{\partial q_{\mathrm{t}}}{\partial z}\right) M_{\mathrm{u}, \mathrm{sh}},
$$

where $E_{\text {tr }}$ is the entrainment rate, $D_{\mathrm{tr}}$ is the detrainment rate, and $\bar{q}_{\mathrm{t}}$ is the MMR of the mean environmental total water. The fractional entrainment and detrainment rates are denoted as $\varepsilon$ and $\delta$, then

$E_{\mathrm{tr}}=\varepsilon M_{\mathrm{u}, \mathrm{sh}}, \quad D_{\mathrm{tr}}=\delta M_{\mathrm{u}, \mathrm{sh}}$.

Finally, attaining the updraft dilution equations

$$
\begin{aligned}
& \frac{\partial M_{\mathrm{u}, \mathrm{sh}}}{\partial z}=M_{\mathrm{u}, \mathrm{sh}}(\varepsilon-\delta), \\
& \frac{\partial q_{\mathrm{t}, \mathrm{u}}}{\partial z}=\varepsilon\left(\bar{q}_{\mathrm{t}}-q_{\mathrm{t}, \mathrm{u}}\right)+\frac{\partial q_{\mathrm{t}}}{\partial z} .
\end{aligned}
$$

Similarly, the updraft dilution equation for the tagged total water is expressed as

$$
\frac{\partial q_{\mathrm{t}, \mathrm{u}, \mathrm{tg}}^{k}}{\partial z}=\varepsilon\left(\bar{q}_{\mathrm{t}, \mathrm{tg}}^{k}-q_{\mathrm{t}, \mathrm{u}, \mathrm{tg}}^{k}\right)+\frac{\partial q_{\mathrm{t}, \mathrm{tg}}^{k}}{\partial z} .
$$

Equation (A5) of Bretherton et al. (2004) is used to calculate $q_{\mathrm{t}, \mathrm{u}}$, as well as $q_{\mathrm{t}, \mathrm{u}, \mathrm{tg}}^{k}$, in the shallow convection. In this scheme, because the detrainment of cloud water and ice $\left(D\left(q_{1}\right)\right.$ and $\left.D\left(q_{\mathrm{i}}\right)\right)$ is assumed to be proportional to the total water detrainment and the detrained air is assumed to be a representative of cumulus updraft (Park and Bretherton, 2009), we use the ratio of tagged total water in the updraft $q_{\mathrm{t}, \mathrm{u}, \mathrm{tg}}^{k}$ and the corresponding sum to distribute the detrainment of tagged cloud water and ice $\left(D\left(q_{1, \mathrm{tg}}^{k}\right)\right.$ and $\left.D\left(q_{\mathrm{i}, \mathrm{tg}}^{k}\right)\right)$ :

$D\left(q_{1, \mathrm{tg}}^{k}\right)=\left(\frac{q_{\mathrm{t}, \mathrm{u}, \mathrm{tg}}^{k}}{\sum_{k=1}^{n} q_{\mathrm{t}, \mathrm{u}, \mathrm{tg}}^{k}}\right) \times D\left(q_{1}\right)$,

$D\left(q_{\mathrm{i}, \mathrm{tg}}^{k}\right)=\left(\frac{q_{\mathrm{t}, \mathrm{u}, \mathrm{tg}}^{k}}{\sum_{k=1}^{n} q_{\mathrm{t}, \mathrm{u}, \mathrm{tg}}^{k}}\right) \times D\left(q_{\mathrm{i}}\right)$.

This ratio is also applied to the calculations of in-cumulus tagged condensates and the production rates of tagged rain/snow by cumulus expulsion of condensates to the environment. Tagged condensate tendencies for compensating subsidence or upwelling, the tagged condensate tendencies due to detrained cloud water and ice without precipitation contribution, and the updraft/penetrative entrainment mass flux of tagged total water are calculated using the same equations for the original water-related quantities in this scheme. Similar to the calculation of the tendency of water vapour, the tendency of tagged water vapour is computed as the 
difference between the tendency of tagged total water and the tendencies of tagged condensates in non-precipitating processes within the shallow convection scheme. The shallow convection scheme relates precipitation evaporation rate $\left(\frac{\partial q_{\mathrm{v}}}{\partial t}\right)_{\text {sh_evap }}$ to shallow convection precipitation flux $Q_{\mathrm{sh}}$, similar to the deep convection scheme of CAM5.1. Therefore, we use an assumed expression similar to Eq. (4) to calculate the tagged precipitation evaporation rate at a level $m$ :

$$
\begin{aligned}
& \left(\frac{\partial q_{\mathrm{v}, \mathrm{tg}}^{k}}{\partial t}\right)_{\text {sh_evap }}= \\
& \begin{cases}k_{e}\left(1-\mathrm{RH}_{m}\right) \frac{\left(Q_{m, \mathrm{tg}}^{k}\right)_{\mathrm{sh}}}{\sqrt{\sum_{k=1}^{n}\left(Q_{m, \mathrm{tg}}^{k}\right)_{\mathrm{sh}}}} \text { if } \sum_{k=1}^{n}\left(Q_{m, \mathrm{tg}}^{k}\right)_{\mathrm{sh}} \neq 0 \\
0, & \text { if } \sum_{k=1}^{n}\left(Q_{m, \mathrm{tg}}^{k}\right)_{\mathrm{sh}}=0\end{cases}
\end{aligned}
$$

where $\left(Q_{m, \mathrm{tg}}^{k}\right)_{\mathrm{sh}}$ is the tagged precipitation flux at the top interface of level $m$.

\subsection{Cloud macrophysics}

Park et al. (2014) provided a detailed description of CAM5.1's cloud macrophysics, in which cloud fractions, horizontal and vertical overlapping structures of clouds, and net condensation rates of water vapour into cloud droplets and ice are computed. Since the tendencies of water substances caused by cumulus convection have been calculated in deep and shallow convection schemes, we focus on the treatment of the tagged stratus fraction and net condensation rates of tagged water vapour in stratus clouds in this section.

The separate liquid stratus fraction $a_{1, \text { st }}$ is a unique function of grid-mean relative humidity $(\mathrm{RH})$ over water, $\bar{u}_{1} \equiv$ $\bar{q}_{\mathrm{v}} / \bar{q}_{\mathrm{s}, \mathrm{w}}$, where $\bar{q}_{\mathrm{v}}$ is the grid-mean water-vapour-specific humidity and $\bar{q}_{\mathrm{s}, \mathrm{w}}$ is the grid-mean saturation-specific humidity over water, which is shown in Eq. (3) of Park et al. (2014). Then the single-phase (no separate liquid and ice phases) liquid stratus fraction is

$A_{1, \mathrm{st}}=\left(1-A_{\mathrm{cu}}\right) a_{1, \mathrm{st}}$.

Here $A_{\mathrm{cu}}$ is the total cumulus fraction.

We allocate the tagged liquid stratus fraction $A_{1, \mathrm{st} \text {,tg }}^{k}$, which depends on the ratio of grid-mean tagged water-vapourspecific humidity $\bar{q}_{\mathrm{v}, \mathrm{tg}}^{k}$ and the corresponding sum, expressed as

$$
A_{1, \mathrm{st}, \mathrm{tg}}^{k}=\left(\frac{\bar{q}_{\mathrm{v}, \mathrm{tg}}^{k}}{\sum_{k=1}^{n} \bar{q}_{\mathrm{v}, \mathrm{tg}}^{k}}\right) A_{1, \mathrm{st}} .
$$

The tagged grid-mean liquid stratus condensate $\bar{q}_{1, \mathrm{a}, \mathrm{tg}}^{k}$ is calculated in the same way as the grid-mean liquid stratus condensate $\bar{q}_{1, \mathrm{a}}$, but $A_{1, \mathrm{st}, \mathrm{tg}}^{k}$ is substituted for $A_{1, \mathrm{st}}$ :

$\bar{q}_{1, \mathrm{a}, \mathrm{tg}}^{k}=A_{1, \mathrm{st}, \mathrm{tg}}^{k} \times q_{1, \mathrm{st}}$.

Here, $q_{1, \mathrm{st}}$ is the in-stratus liquid water content. Similar to $a_{1, \mathrm{st}}$, the ice stratus fraction $a_{\mathrm{i}, \mathrm{st}}$ is a function of the gridmean total ice RH over ice, $\bar{v}_{\mathrm{i}} \equiv\left(\bar{q}_{\mathrm{v}}+\bar{q}_{\mathrm{i}}\right) / \bar{q}_{\mathrm{s}, \mathrm{i}}$, where $\bar{q}_{\mathrm{i}}$ is the grid-mean ice-specific humidity and $\bar{q}_{\mathrm{s}, \mathrm{i}}$ is the grid-mean saturation-specific humidity over ice, as shown in Eq. (4) of Park et al. (2014). Similar to $A_{1, \mathrm{st}}$, the single-phase ice stratus fraction is calculated as

$A_{\mathrm{i}, \mathrm{st}}=\left(1-A_{\mathrm{cu}}\right) a_{\mathrm{i}, \mathrm{st}}$.

As in the treatment of $A_{1, \mathrm{st} \text {,tg }}^{k}$, the tagged ice stratus fraction $A_{\mathrm{i}, \mathrm{st}, \mathrm{tg}}^{k}$ is computed based on the ratio of grid-meantotal tagged ice-specific humidity $\left(\bar{q}_{\mathrm{v}, \mathrm{tg}}^{k}+\bar{q}_{\mathrm{i}, \mathrm{tg}}^{k}\right)$ and the corresponding sum:

$A_{\mathrm{i}, \mathrm{st}, \mathrm{tg}}^{k}=\left[\frac{\left(\bar{q}_{\mathrm{v}, \mathrm{tg}}^{k}+\bar{q}_{\mathrm{i}, \mathrm{tg}}^{k}\right)}{\sum_{k=1}^{n}\left(\bar{q}_{\mathrm{v}, \mathrm{tg}}^{k}+\bar{q}_{\mathrm{i}, \mathrm{tg}}^{k}\right)}\right] A_{\mathrm{i}, \mathrm{st} .}$

The tagged grid-mean ice stratus condensate $\bar{q}_{\mathrm{i}, \mathrm{a}, \mathrm{tg}}^{k}$ is calculated in the same way as the grid-mean ice stratus condensate $\bar{q}_{\mathrm{i}, \mathrm{a}}$ :

$\bar{q}_{\mathrm{i}, \mathrm{a}, \mathrm{tg}}^{k}=A_{\mathrm{i}, \mathrm{st}, \mathrm{tg}}^{k} \times q_{\mathrm{i}, \mathrm{st}}$.

Here, $q_{\mathrm{i}, \mathrm{st}}$ is the in-stratus ice water content. Using the same formula as for the calculation of the grid-mean ambient water-vapour-specific humidity, the tagged grid-mean ambient water-vapour-specific humidity $\bar{q}_{\mathrm{v}, \mathrm{a}, \mathrm{tg}}^{k}$ is computed as follows:

$\bar{q}_{\mathrm{v}, \mathrm{a}, \mathrm{tg}}^{k}=\bar{q}_{\mathrm{v}, \mathrm{tg}}^{k}+\bar{q}_{1, \mathrm{tg}}^{k}+\bar{q}_{\mathrm{i}, \mathrm{tg}}^{k}-\bar{q}_{\mathrm{l}, \mathrm{a}, \mathrm{tg}}^{k}-\bar{q}_{\mathrm{i}, \mathrm{a}, \mathrm{tg}}^{k}$.

In CAM5.1, Park et al. (2014) defined the grid-mean net condensation rate of water vapour into liquid stratus condensate $\bar{Q}_{1}$ as the time change of $\bar{q}_{1, \mathrm{a}}$ minus the external forcing (all processes except stratus macrophysics, including stratus microphysics, moisture turbulence, advection, and convection) of cloud droplets $\bar{F}_{1}$ :

$\bar{Q}_{1}=\dot{\bar{q}}_{1, \mathrm{a}}-\bar{F}_{1}=A_{1, \mathrm{st}} \dot{q}_{1, \mathrm{st}}+\alpha q_{1, \mathrm{st}} \dot{A}_{1, \mathrm{st}}-\bar{F}_{1}$,

where $\dot{\bar{q}}_{1, \mathrm{a}}, \dot{q}_{1, \mathrm{st}}$, and $\dot{A}_{1, \mathrm{st}}$ are the time tendency of $\bar{q}_{1, \mathrm{a}}, q_{1, \mathrm{st}}$, and $A_{1, \mathrm{st}}$, respectively, during $\Delta t=1800 \mathrm{~s}$. In CAM5.1, $\alpha=$ 0.1 is the ratio of newly formed or dissipated stratus to the preexisting $q_{1, \mathrm{st}}$. Similarly, the tagged grid-mean net condensation rate $\bar{Q}_{1, \mathrm{tg}}^{k}$ is calculated as

$$
\begin{aligned}
\bar{Q}_{1, \mathrm{tg}}^{k} & =\dot{\bar{q}}_{1, \mathrm{a}, \mathrm{tg}}^{k}-\bar{F}_{1, \mathrm{tg}}^{k} \\
& =A_{1, \mathrm{st}, \mathrm{tg}}^{k} \dot{q}_{1, \mathrm{st}}+\alpha q_{1, \mathrm{st}}\left(R \dot{A}_{1, \mathrm{st}}+A_{1, \mathrm{st}} \dot{R}\right)-\bar{F}_{1, \mathrm{tg}}^{k},
\end{aligned}
$$


and $R=\frac{\bar{q}_{\mathrm{v}, \mathrm{tg}}^{k}}{\sum_{k=1}^{n} \bar{q}_{\mathrm{v}, \mathrm{tg}}^{k}}$.

Here, $\dot{R}$ is the tendency of $R$ during $\Delta t$, and $\bar{F}_{1, \mathrm{tg}}^{k}$ is the changes of tagged cloud droplets in processes such as microphysics, moisture turbulence, advection, and deep and shallow convections.

\subsection{Cloud microphysics}

The CAM5.1 model uses the double-moment cloud microphysical scheme described in Morrison and Gettelman (2008) and a modified treatment of ice supersaturation and ice nucleation from Gettelman et al. (2010). In addition, CAM5.1's stratus microphysics is formulated using a singlephase stratus fraction $A_{\text {st }}$, which is assumed as the maximum overlap between $A_{1, \text { st }}$ and $A_{\mathrm{i}, \mathrm{st}}$ (Park et al., 2014). In this study, the same assumption is applied to each tagged single-phase stratus fraction $A_{\mathrm{st} t \mathrm{tg}}^{k}$. The microphysical processes in CAM5.1 include condensation/deposition, evaporation/sublimation, autoconversion of cloud droplets and ice to form rain and snow, accretion of cloud droplets and ice by rain or by snow, heterogeneous freezing, homogeneous freezing, melting, sedimentation, activation of cloud droplets, and primary ice nucleation. Detailed formulations for these microphysical processes are described in Morrison and Gettelman (2008).

\subsubsection{Condensation/deposition and evaporation/sublimation of cloud water and ice}

In CAM5.1, the net grid-mean evaporation/condensation rate of cloud water and ice (condensation minus evaporation) $Q$ is calculated following Zhang et al. (2003). In this microphysics scheme, the total grid-scale condensation rates of tagged ice and tagged cloud water, as well as the total gridscale evaporation rates of tagged cloud water and tagged ice, are calculated using the same formulas but the tagged variables are substituted for the corresponding original variables:

$$
\begin{aligned}
& \left(\frac{\partial q_{\mathrm{i}, \mathrm{tg}}^{k}}{\partial t}\right)_{\mathrm{cond}}=\min \left[A_{\mathrm{st}, \mathrm{tg}}^{k} A, A_{\mathrm{st}, \mathrm{tg}}^{k} Q+\frac{q_{\mathrm{l}, \mathrm{tg}}^{k}}{\Delta t}\right], Q>0, \\
& \left(\frac{\partial q_{1, \mathrm{tg}}^{k}}{\partial t}\right)_{\text {cond }}=\max \left[A_{\mathrm{st}, \mathrm{tg}}^{k} Q-\left(\frac{\partial q_{\mathrm{i}, \mathrm{g}}^{k}}{\partial t}\right)_{\text {cond }}, 0\right], Q>0, \\
& \left(\frac{\partial q_{1, \mathrm{tg}}^{k}}{\partial t}\right)_{\text {evap }}=\max \left(A_{\mathrm{st}, \mathrm{tg}}^{k},-\frac{q_{1, \mathrm{~g}}^{k}}{\Delta t}\right),<0, \\
& \left(\frac{\partial q_{\mathrm{i}, \mathrm{tg}}^{k}}{\partial t}\right)_{\text {evap }}=\max \left[A_{\mathrm{st, \textrm {g }}}^{k} Q-\left(\frac{\partial q_{\mathrm{l}, \mathrm{tg}}^{k}}{\partial t}\right)_{\text {evap }},-\frac{q_{\mathrm{i}, \mathrm{tg}}^{k}}{\Delta t}\right], Q<0,
\end{aligned}
$$

where $A$ is the in-cloud deposition rate of water vapour onto cloud ice (see Eq. 21 of Morrison and Gettelman, 2008).

\subsubsection{Conversion of cloud water to rain and conversion of cloud ice to snow}

The grid-mean autoconversion and accretion rates of water cloud in CAM5.1 are expressed in Eqs. (27) and (28) of Morrison and Gettelman (2008). The two rates can be regarded as a term multiplied by $A_{\mathrm{st}}$. Therefore, the grid-mean autoconversion and accretion rates of tagged water cloud can be calculated in the same formula but $A_{\mathrm{st}, \mathrm{tg}}^{k}$ is substituted for $A_{\text {st }}$ :

$\left(\frac{\partial q_{1, \mathrm{tg}}^{k}}{\partial t}\right)_{\text {auto }}=\frac{A_{\mathrm{st}, \mathrm{tg}}^{k}}{A_{\mathrm{st}}}\left(\frac{\partial q_{1}}{\partial t}\right)_{\text {auto }}=-\left(\frac{\partial q_{\mathrm{r}, \mathrm{tg}}^{k}}{\partial t}\right)_{\text {auto }}$,

$\left(\frac{\partial q_{1, \mathrm{tg}}^{k}}{\partial t}\right)_{\mathrm{accr}}=\frac{A_{\mathrm{st}, \mathrm{tg}}^{k}}{A_{\mathrm{st}}}\left(\frac{\partial q_{1}}{\partial t}\right)_{\mathrm{accr}}=-\left(\frac{\partial q_{\mathrm{r}, \mathrm{tg}}^{k}}{\partial t}\right)_{\mathrm{accw}}$,

where $q_{\mathrm{r}, \mathrm{tg}}^{k}$ is the MMR of tagged stratiform rain.

Similarly, the grid-mean autoconversion rate of ice to form snow can be seen as a term multiplied by $A_{\text {st }}$ (see Eq. 29 of Morrison and Gettelman, 2008), as well as the accretion of ice following Lin et al. (1983). Thus, the autoconversion and accretion rates of tagged ice to form snow are expressed as

$$
\begin{aligned}
& \left(\frac{\partial q_{\mathrm{i}, \mathrm{tg}}^{k}}{\partial t}\right)_{\text {auto }}=\frac{A_{\mathrm{st}, \mathrm{tg}}^{k}}{A_{\mathrm{st}}}\left(\frac{\partial q_{\mathrm{i}}}{\partial t}\right)_{\text {auto }}=-\left(\frac{\partial q_{\mathrm{s}, \mathrm{tg}}^{k}}{\partial t}\right)_{\text {auto }}, \\
& \left(\frac{\partial q_{\mathrm{i}, \mathrm{tg}}^{k}}{\partial t}\right)_{\mathrm{accs}}=\frac{A_{\mathrm{st}, \mathrm{tg}}^{k}}{A_{\mathrm{st}}}\left(\frac{\partial q_{\mathrm{i}}}{\partial t}\right)_{\mathrm{accs}}=-\left(\frac{\partial q_{\mathrm{s}, \mathrm{tg}}^{k}}{\partial t}\right)_{\mathrm{acci}},
\end{aligned}
$$

where $q_{\mathrm{s}, \mathrm{tg}}^{k}$ is the MMR of tagged stratiform snow.

\subsubsection{Other collection processes}

The accretion of cloud water by snow $\left(\frac{\partial q_{1}}{\partial t}\right)_{\text {accs }}=$ $-\left(\frac{\partial q_{\mathrm{s}}}{\partial t}\right)_{\text {accw }}$ is attained by the continuous collection equation, whose collection efficiency is a function of the Stokes number following Thompson et al. (2004). Similar to the calculation of $\left(\frac{\partial q_{1}}{\partial t}\right)_{\text {auto }},\left(\frac{\partial q_{1}}{\partial t}\right)_{\text {accs }}$ can be regarded as a term multiplied by $A_{1, \mathrm{st}}$. Thus, $\left(\frac{\partial q_{\mathrm{l,tg}}^{k}}{\partial t}\right)_{\text {accs }}$ is computed using the same equation but by multiplying it by $A_{1, \mathrm{st}, \mathrm{tg}}^{k}$ instead of $A_{1, \mathrm{st}}$ :

$\left(\frac{\partial q_{1, \mathrm{tg}}^{k}}{\partial t}\right)_{\mathrm{accs}}=\frac{A_{1, \mathrm{st} t \mathrm{tg}}^{k}}{A_{1, \mathrm{st}}}\left(\frac{\partial q_{1}}{\partial t}\right)_{\mathrm{accs}}=-\left(\frac{\partial q_{\mathrm{s}, \mathrm{tg}}^{k}}{\partial t}\right)_{\mathrm{accw}}$.

The collection of rain by snow $\left(\frac{\partial q_{\mathrm{r}}}{\partial t}\right)_{\text {coll }}=-\left(\frac{\partial q_{\mathrm{s}}}{\partial t}\right)_{\text {coll }}$ can also be regarded as a term multiplied by $A_{\mathrm{st}}$. Therefore, $\left(\frac{\partial q_{\mathrm{rtg}}^{k}}{\partial t}\right)_{\text {coll }}$ is computed using the same formula but by multiplying it by $A_{\mathrm{st}, \mathrm{tg}}^{k}$ instead of $A_{\mathrm{st}}$ :

$\left(\frac{\partial q_{\mathrm{r}, \mathrm{tg}}^{k}}{\partial t}\right)_{\mathrm{coll}}=\frac{A_{\mathrm{st}, \mathrm{tg}}^{k}}{A_{\mathrm{st}}}\left(\frac{\partial q_{\mathrm{r}}}{\partial t}\right)_{\mathrm{coll}}=-\left(\frac{\partial q_{\mathrm{s}, \mathrm{tg}}^{k}}{\partial t}\right)_{\mathrm{coll}}$. 


\subsubsection{Freezing of cloud water and rain}

The heterogeneous freezing of cloud water and rain is considered in CAM5.1 (Reisner et al., 1998; Morrison and Pinto, 2005). The heterogeneous freezing of tagged cloud water is computed using the same formula as that of original cloud water, but by multiplying with $A_{1, \mathrm{st}, \mathrm{tg}}^{k}$ instead of $A_{1, \mathrm{st}}$ :

$\left(\frac{\partial q_{1, \mathrm{tg}}^{k}}{\partial t}\right)_{\text {het }}=\frac{A_{1, \mathrm{st}, \mathrm{tg}}^{k}}{A_{1, \mathrm{st}}}\left(\frac{\partial q_{1}}{\partial t}\right)_{\text {het }}$.

Similarly, the heterogeneous freezing of tagged rain is computed using the same formula as that of original rain, but by multiplying it by $A_{\mathrm{st}, \mathrm{tg}}^{k}$ instead of $A_{\mathrm{st}}$ :

$\left(\frac{\partial q_{\mathrm{r}, \mathrm{tg}}^{k}}{\partial t}\right)_{\text {het }}=\frac{A_{\mathrm{st}, \mathrm{tg}}^{k}}{A_{\mathrm{st}}}\left(\frac{\partial q_{\mathrm{r}}}{\partial t}\right)_{\text {het }}$.

The homogeneous freezing of tagged cloud droplets and tagged rain are computed using the same equations as those of the original cloud droplets and rain, but $q_{1, \mathrm{tg}}^{k}$ and $S_{\mathrm{r}, \mathrm{tot}, \mathrm{tg}}^{k}$ (the vertical-integrated tagged rain source/sink term) are substituted for the original quantities:

$$
\begin{aligned}
& \left(\frac{\partial q_{1, \mathrm{tg}}^{k}}{\partial t}\right)_{\mathrm{hom}}=\frac{\left(\frac{\partial q_{\mathrm{l}}}{\partial t}\right)_{\mathrm{hom}}}{\left(\frac{q_{\mathrm{l}}}{\Delta t}\right)}\left(\frac{q_{\mathrm{l}, \mathrm{tg}}^{k}}{\Delta t}\right)=-\left(\frac{\partial q_{\mathrm{i}, \mathrm{tg}}^{k}}{\partial t}\right)_{\mathrm{hom}} \\
& \left(\frac{\partial q_{\mathrm{r}, \mathrm{tg}}^{k}}{\partial t}\right)_{\text {hom }}=\frac{\left(\frac{\partial q_{\mathrm{r}}}{\partial t}\right)_{\text {hom }}}{S_{\mathrm{r}, \mathrm{tot}}} S_{\mathrm{r}, \mathrm{tot}, \mathrm{tg}}^{k}=-\left(\frac{\partial q_{\mathrm{s}, \mathrm{tg}}^{k}}{\partial t}\right)_{\mathrm{hom}} .
\end{aligned}
$$

\subsubsection{Melting of cloud ice and snow}

Similar to the calculations of the homogeneous freezing of cloud water and rain, the melting of tagged ice and tagged snow are computed using the same equations as those of the original ice and snow, but $q_{\mathrm{i}, \mathrm{tg}}^{k}$ and $S_{\mathrm{s}, \mathrm{tot}, \mathrm{tg}}^{k}$ (the verticalintegrated tagged snow source/sink term) are substituted for the original quantities:

$$
\begin{aligned}
& \left(\frac{\partial q_{\mathrm{i}, \mathrm{tg}}^{k}}{\partial t}\right)_{\text {melt }}=\frac{\left(\frac{\partial q_{\mathrm{i}}}{\partial t}\right)_{\mathrm{melt}}}{\left(\frac{q_{\mathrm{i}}}{\Delta t}\right)}\left(\frac{q_{\mathrm{i}, \mathrm{g}}^{k}}{\Delta t}\right)=-\left(\frac{\partial q_{\mathrm{l}, \mathrm{tg}}^{k}}{\partial t}\right)_{\text {melt }} \\
& \left(\frac{\partial q_{\mathrm{s}, \mathrm{tg}}^{k}}{\partial t}\right)_{\text {melt }}=\frac{\left(\frac{\partial q_{\mathrm{s}}}{\partial t}\right)_{\text {melt }}}{S_{\mathrm{s}, \mathrm{tot}}^{k}} S_{\mathrm{s}, \mathrm{tot}, \mathrm{tg}}^{k}=-\left(\frac{\partial q_{\mathrm{r}, \mathrm{tg}}^{k}}{\partial t}\right)_{\text {melt }} .
\end{aligned}
$$

\subsubsection{Evaporation/sublimation of precipitation}

For the calculations of the evaporation of tagged rain and the sublimation of tagged snow, both are calculated using the same formula as original quantities but $A_{\mathrm{st}, \mathrm{tg}}^{k}$ is substituted for $A_{\mathrm{st}}$ :

$$
\left(\frac{\partial q_{\mathrm{r}, \mathrm{tg}}^{k}}{\partial t}\right)_{\text {evap }}=\frac{A_{\mathrm{st}, \mathrm{tg}}^{k}}{A_{\mathrm{st}}}\left(\frac{\partial q_{\mathrm{r}}}{\partial t}\right)_{\text {evap }},
$$

$\left(\frac{\partial q_{\mathrm{s}, \mathrm{tg}}^{k}}{\partial t}\right)_{\text {evap }}=\frac{A_{\mathrm{st}, \mathrm{tg}}^{k}}{A_{\mathrm{st}}}\left(\frac{\partial q_{\mathrm{s}}}{\partial t}\right)_{\text {evap }}$.

\subsubsection{Sedimentation of cloud water and ice}

The time tendencies $\left(\left(\frac{\partial q_{1}}{\partial t}\right)_{\text {sed }}\right.$ and $\left.\left(\frac{\partial q_{\mathrm{i}}}{\partial t}\right)_{\text {sed }}\right)$ of cloud water and ice for sedimentation, as well as those of tagged cloud water and tagged ice $\left(\left(\frac{\partial q_{1, \mathrm{~g}}^{k}}{\partial t}\right)_{\mathrm{sed}}\right.$ and $\left.\left(\frac{\partial q_{\mathrm{i}, \mathrm{g}}^{k}}{\partial t}\right)_{\mathrm{sed}}\right)$, are calculated with a simple forward differencing scheme in the vertical dimension (Morrison and Gettelman, 2008). In CAM5.1, the sedimentation of cloud water and ice can lead to evaporation or sublimation when the cloud fraction at the level above is larger than the cloud fraction at the given level and the evaporation or condensation rate is assumed to be proportional to the difference in cloud fraction between the levels. This assumption is also applied to calculate the evaporation of tagged cloud water or sublimation of tagged ice, when the tagged cloud fraction at the level above is larger than the tagged cloud fraction at the given level.

\subsubsection{The diagnosis of precipitation}

The grid-scale time tendency of the MMR of precipitation $q_{\mathrm{p}}$ in CAM5.1's microphysics is expressed as

$\frac{\partial q_{\mathrm{p}}}{\partial t}=\frac{1}{\rho} \frac{\partial\left(V_{\mathrm{q}} \rho q_{\mathrm{p}}\right)}{\partial z}+S_{\mathrm{q}}$,

where $z$ is height, $V_{\mathrm{q}}$ is the mass-weighted terminal fall speeds (see Eq. 18 of Morrison and Gettelman, 2008), and $S_{\mathrm{q}}$ is the grid-mean source/sink terms for $q_{\mathrm{p}}$ :

$$
\begin{gathered}
S_{\mathrm{q}}=\left(\frac{\partial q_{\mathrm{p}}}{\partial t}\right)_{\text {auto }}+\left(\frac{\partial q_{\mathrm{p}}}{\partial t}\right)_{\mathrm{accw}}+\left(\frac{\partial q_{\mathrm{p}}}{\partial t}\right)_{\text {acci }}+\left(\frac{\partial q_{\mathrm{p}}}{\partial t}\right)_{\text {het }} \\
+\left(\frac{\partial q_{\mathrm{p}}}{\partial t}\right)_{\text {hom }}+\left(\frac{\partial q_{\mathrm{p}}}{\partial t}\right)_{\text {melt }}+\left(\frac{\partial q_{\mathrm{p}}}{\partial t}\right)_{\text {evap }}+\left(\frac{\partial q_{\mathrm{p}}}{\partial t}\right)_{\text {coll }} .
\end{gathered}
$$

For the diagnostic treatments of tagged rain and tagged snow, the $q_{\mathrm{p}}$ in Eqs. (40) and (41) is replaced by $q_{\mathrm{r}, \mathrm{tg}}^{k}$ and $q_{\mathrm{s}, \mathrm{tg}}^{k}$, respectively.

\subsection{Advection}

The finite volume dynamical core is chosen in this study due to its excellent properties for tracer transport (Rasch et al., 2006). The CAM5.1 model can be driven by offline meteorological fields (Lamarque et al., 2012) following the procedure initially developed for the Model of Atmospheric Transport and Chemistry (MARCH) (Rasch et al., 1997). This procedure allows for more accurate comparisons between measurements of atmospheric composition and CAM5.1's output (Lamarque et al., 2012). In this study, the external meteorological fields are obtained from Modern Era Retrospective analysis for Research and Applications (MERRA) data sets 
(Rienecker et al., 2011), whose horizontal resolution is identical to CAM5.1's and time resolution is $6 \mathrm{~h}$. In the simulation procedure, the zonal and meridional wind components, air temperature, surface pressure, surface temperature, surface geopotential, surface stress, and sensible and latent heat fluxes are read from the MERRA data sets to drive CAM5.1 (Lamarque et al., 2012). To prevent jumps, all input fields are linearly interpolated at time steps between the reading times. Later, these fields are used to drive the CAM5.1's parameterisations to generate the necessary variables and calculate subgrid-scale transport and the hydrological cycle (Lamarque et al., 2012). Temporal evolutions of $q_{\mathrm{v}, \mathrm{tg}}^{k}, q_{1, \mathrm{tg}}^{k}$, and $q_{\mathrm{i}, \mathrm{tg}}^{k}$ in the advective process are treated in the same manner as other constituents without any modification.

\subsection{Vertical diffusion}

CAM5.1's moist turbulence scheme is taken from the scheme presented by Bretherton and Park (2009), which calculates the vertical transport of heat, moisture, horizontal momentum, and tracers by symmetric turbulence. The vertical diffusion of tagged water substances is treated by the procedure in the same way as other constituents without any modification.

\subsection{Adjustment}

Ideally, the differences between the MMRs of water substances and the summed MMRs of all corresponding tagged water substances should be zero. However, there are exceptional differences in a few grid points (see Fig. S6 in the Supplement). Figures S1-S5 show comparisons between the tendencies of the original water substances and the sum of the tendencies of the tagged water substances for the relevant physical processes described in Sect. 2.1 through 2.6. Although differences are small for most grid points, some abnormal values still appear randomly. For tagged water vapour, evident biases mainly occur in deep convection, cloud processes (cloud macrophysics and microphysics), and advection in the tropics; for tagged cloud droplets, the apparent biases generally occur in cloud processes; for tagged cloud ice, the main differences occur in cloud processes, advection, and vertical diffusion. Non-linearities in the calculations of the tendencies of water substances in the physical schemes cause these differences. A bias occurred in one physical parameterisation can affect the calculations of the tendencies of tagged water substances in other parameterisations, since there are interactions among various physical and dynamical processes in CAM5.1. Eventually, clear differences between the summed MMRs of tagged water substances and the MMRs of original water substances may occur, as shown in Fig. S6. To reduce these accumulated biases in the relevant physical schemes, additional criteria are applied to the relevant quantities of the tagged water substances:
1. If the positive or negative sign of the tendency of a tagged water substance is identical to the sign of the tendency of the original water substance, the absolute value of the tendency of the tagged water substance should not be larger than that of the original water substance. If their signs are different, the tendency of the tagged water substance is set to zero. This adjustment can be expressed as

$$
\left\{\begin{array}{l}
\frac{\partial q_{\mathrm{tg}}^{k}}{\partial t}= \\
\min \left(\frac{\partial q_{\mathrm{tg}}^{k}}{\partial t}, \frac{\partial q}{\partial t}\right), \text { if } \frac{\partial q_{\mathrm{tg}}^{k}}{\partial t} \geq 0 \text { and } \frac{\partial q}{\partial t} \geq 0 \\
\max \left(\frac{\partial q_{\mathrm{tg}}^{k}}{\partial t}, \frac{\partial q}{\partial t}\right), \text { if } \frac{\partial q_{\mathrm{tg}}^{k}}{\partial t} \leq 0 \text { and } \frac{\partial q}{\partial t}<0 \\
0, \text { if }\left(\frac{\partial q_{\mathrm{tg}}^{k}}{\partial t}<0 \text { and } \frac{\partial q}{\partial t} \geq 0\right) \\
\text { or }\left(\frac{\partial q_{\mathrm{tg}}^{k}}{\partial t}>0 \text { and } \frac{\partial q}{\partial t}<0\right)
\end{array}\right.
$$

where $\frac{\partial q_{\mathrm{tg}}^{k}}{\partial t}$ and $\frac{\partial q}{\partial t}$ represent the tendency of the tagged water substances and the tendency of the corresponding original water substance in a given physical process, respectively.

2. After the adjustment in Eq. (42) has been applied, the sum of the tendencies of all tagged water substances should be equal to the tendency of the corresponding original water substance in each scheme. This adjustment can be described as follows:

$$
\frac{\partial q_{\mathrm{tg}}^{k}}{\partial t}=\left\{\begin{array}{cc}
R_{\mathrm{q}}\left(\frac{\partial q_{\mathrm{tg}}^{k}}{\partial t}\right), & \text { if } \sum_{k=1}^{n}\left(\frac{\partial q_{\mathrm{tg}}^{k}}{\partial t}\right) \neq 0, \\
\text { here } R_{\mathrm{q}}=\frac{\frac{\partial q}{\partial t}}{\sum_{k=1}^{n}\left(\frac{\partial q_{\mathrm{g}}^{k}}{\partial t}\right)} \\
\frac{1}{n}\left(\frac{\partial q}{\partial t}\right), & \text { if } \sum_{k=1}^{n}\left(\frac{\partial q_{\mathrm{tg}}^{k}}{\partial t}\right)=0 .
\end{array}\right.
$$

\section{Results and discussion}

\subsection{Model assessment}

Numaguti (1999) pointed out that the results of the tagged AWTs method suffer from the bias of the model used. Therefore, we first estimate the precipitation in the specified dynamics simulation of CAM5.1, which is compared to the Global Precipitation Climatology Project (GPCP) version 2.2 combined precipitation data set (Huffman and Bolvin, 2011), as shown in Fig. 2. In winter (December, January, and February), high-precipitation zones are located in the tropics of the 


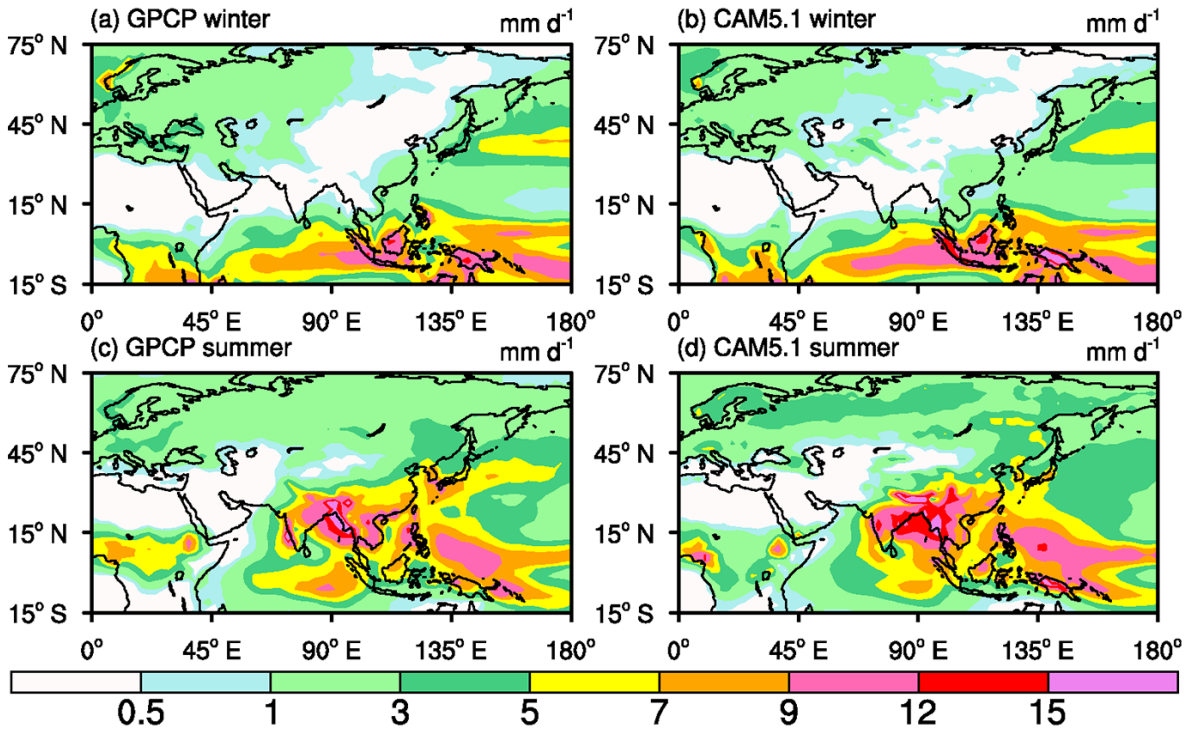

Figure 2. Comparisons between (left) GPCP data and (right) CAM5.1 precipitation simulations during (top) winter and (bottom) summer (10-year averages for 1998-2007).

Southern Hemisphere and in the mid-latitude areas of the NWP. Precipitation is generally less than $3 \mathrm{~mm} \mathrm{day}^{-1}$ over most parts of Eurasia. In summer (June, July, and August), there is heavy precipitation over the southern and southeastern parts of Eurasia and over central Africa. Although CAM5.1 generally shows a bias towards relatively high precipitation in the tropics of the summer hemisphere, the precipitation pattern and amount over Eurasia and its adjacent areas is captured well by CAM5.1. In addition, the water vapour data from the Atmospheric Infrared Sounder (AIRS) and wind field data from National Centers for Environmental Prediction (NCEP) are used to assess the CAM5.1's results, as shown in Fig. S7. Overall, the water vapour and horizontal wind fields can be well simulated by CAM5.1.

\subsection{Terrestrial and oceanic contributions to precipitation over Eurasia}

Figure 3 shows the spatial distribution of the relative contribution of evaporation from all land source regions to precipitation (colours). In winter, evaporation from land source regions generally contributes $\sim 30-60 \%$ to the precipitation over Eurasia. The largest contribution $(\sim 80 \%)$ is located in central China. In summer, $\geq 60 \%$ of precipitation over most parts of Eurasia is supplied by evaporation from land, especially for the inland region where $\geq 80 \%$ of precipitation originates from the land surface. However, the contribution of evaporation from land to summer precipitation over IND, Indo-China Peninsula (ICP), and eastern China is generally less than $50 \%$, due to moisture transport by the Indian summer monsoon and EASM. Overall, the contribution of evaporation from land to precipitation over Eurasia is smaller in winter and larger in summer, which is consistent with the variation of evaporation from the land surface over Eurasia in winter and summer as shown in Fig. 4. The pattern of precipitation contributed by land evaporation is similar to that shown in Numaguti (1999). Our result is close to that of Numaguti (1999) for summer but the contribution of land evaporation to precipitation is evidently larger for winter.

The distributions of the relative contributions of evaporation from the northern Atlantic Ocean (NAO), the extended northern Indian Ocean (includes NIO, BOB, and AS), and the extended north-western Pacific (includes NWP and SCS), which are three important moisture source regions, are shown in Fig. 5. In winter, $\sim 10-60 \%$ of the precipitation over the northern part of Eurasia originates from the NAO, with a westward or north-westward increasing gradient in the relative contribution. The extended northern Indian Ocean supplies moisture for $\sim 10-30 \%$ of the precipitation over northern Africa and southern Asia. The extended north-western Pacific only provides moisture for $10-30 \%$ of the precipitation over the southern and eastern coastal regions of Asia. In summer, evaporation from the NAO only affects precipitation over Europe, with a contribution of $10-30 \%$ to total precipitation. Precipitation areas influenced by the extended northern Indian Ocean extend to EA, while areas impacted by the extended north-western Pacific retreat eastward.

The arrow streamlines in Fig. 3 show the total tropospheric water vapour flux in winter and summer. There is a westward component of water vapour flux over the tropics of both the extended northern Indian Ocean and the extended north-western Pacific in the Northern Hemisphere in winter. In summer, there is a very large north-westward water vapour flux over the NIO, turning north-eastward over the BOB and AS. Over the extended north-western Pacific, there 
(a) Winter

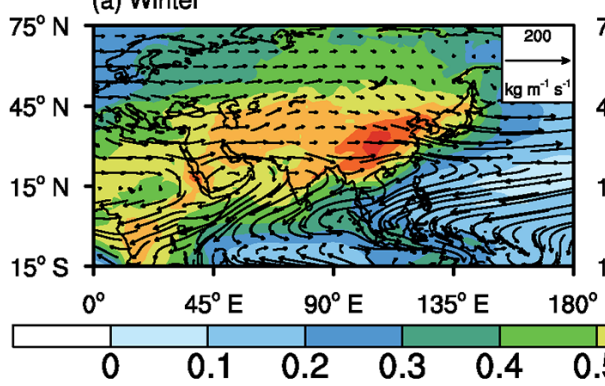

(b) Summer

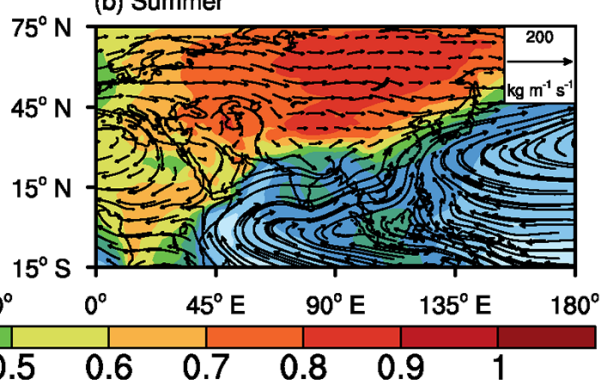

Figure 3. Distribution of the relative contribution to precipitation from all land source regions defined in Fig. 1 (colours; unit: ratio of tagged precipitation over total precipitation) and the vertically integrated total tropospheric water vapour flux (arrow streamlines; unit: $\mathrm{kg} \mathrm{m}^{-1} \mathrm{~s}^{-1}$ ) during (a) winter and (b) summer.

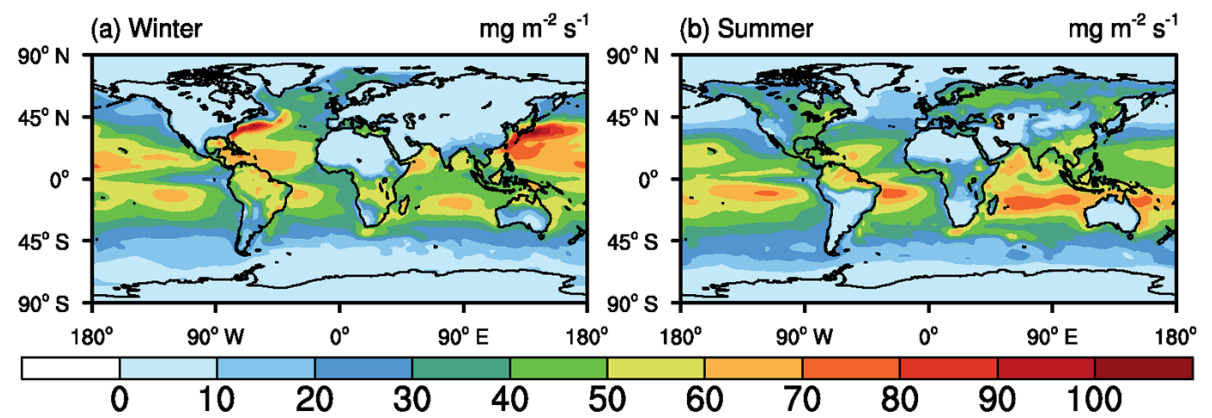

Figure 4. Distribution of CAM5.1's 10-year-averaged surface evaporation flux (unit: $\mathrm{mg} \mathrm{m}^{-2} \mathrm{~s}^{-1}$ ) in (a) winter and (b) summer between 1998 and 2007.

is a northward component of water vapour flux at $30-60^{\circ} \mathrm{N}$ and a westward flux in the tropics between 120 and $180^{\circ} \mathrm{E}$. In addition, Fig. 4 shows strong surface evaporation over the NWP and NAO in winter, whereas evaporation is weaker in summer. In contrast, evaporation over the NIO is larger in summer and smaller in winter. These results help to explain the variations in the contributions of the NAO, extended northern Indian Ocean, and extended north-western Pacific to precipitation in winter and summer as shown in Fig. 5.

The overall contributions from these three oceanic regions are generally less than those in Numaguti (1999). The resolution of the climate model used in Numaguti (1999) is $\sim 5.6^{\circ}$, both in latitudinal and longitudinal direction. The different model resolutions are a probable reason for the different quantitative contributions in our study and that of $\mathrm{Nu}$ maguti (1999). In addition, CAM5.1 is driven by MERRA data, so its surface evaporation flux is approximate to that of MERRA. MERRA land evaporation is larger over southern and eastern Asia and northern Europe compared to other global estimates (Jiménez et al., 2011), and Bosilovich et al. (2011) suggested that MERRA ocean evaporation is lower compared to other reanalyses but is much closer to observation. Therefore, the bias in MERRA surface evaporation may lead to the higher land contribution and lower oceanic contribution to precipitation.

\subsection{Atmospheric moisture source attribution of precipitation and water vapour over the YRV}

Figure $6 \mathrm{a}$ and $\mathrm{b}$ show the time series of evaporative contribution of each source region to precipitation over the YRV. The contributions of evaporation to precipitation from the BOB and AS are lower during autumn-winter and higher during spring-summer with relative contributions of $\leq 3.9 \%$. Chow et al. (2008) (see their Fig. 20a) also found that evaporation from the AS had little impact on precipitation over China. Figures S10-S13 show the distributions of 25 tagged water vapour tracers and 25 tagged precipitations over Eurasia and surrounding areas in winter and summer. Figures S10a and $\mathrm{S} 12 \mathrm{a}$ show that evaporation from the BOB contributes to water vapour and precipitation over the extended northern Indian Ocean in winter, corresponding to the direction of water flux shown in Fig. 3a. The centre of BOB-contributed precipitation $\left(15 \mathrm{mg} \mathrm{m}^{-2} \mathrm{~s}^{-1}\right)$ is located in the south of the TP in summer (Fig. S13a). In addition, the BOB supplies moisture to areas around the north-eastern $\mathrm{BOB}$ in summer (Fig. S11a). The contribution of the SCS to precipitation is also very small $(\leq 3.4 \%)$, which supports the view of Chow et al. (2008), who suggested that the SCS may serve as a pathway for water vapour transport from the south-westerly flow of the Indian summer monsoon and the easterly flow of the north-western Pacific subtropical high. A detailed discus- 
(a) Winter

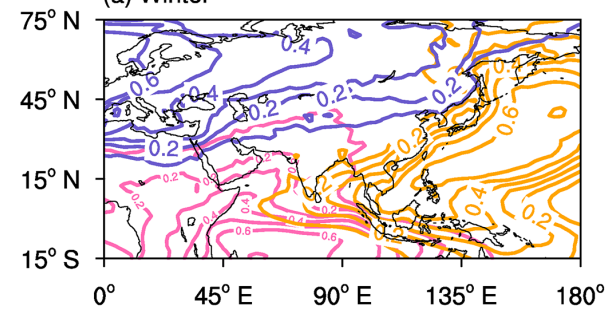

(b) Summer

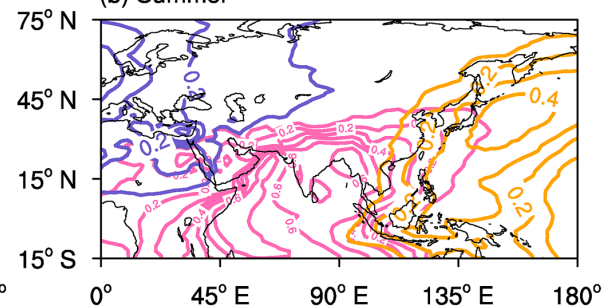

Figure 5. Distributions of the ratios of precipitation (unit: ratio of tagged precipitation over total precipitation) supplied from the NAO (slate blue), the extended northern Indian Ocean (NIO + BOB + AS, pink), and the extended north-western Pacific (NWP + SCS, orange) during (a) winter and (b) summer. Contour interval is 0.1 .
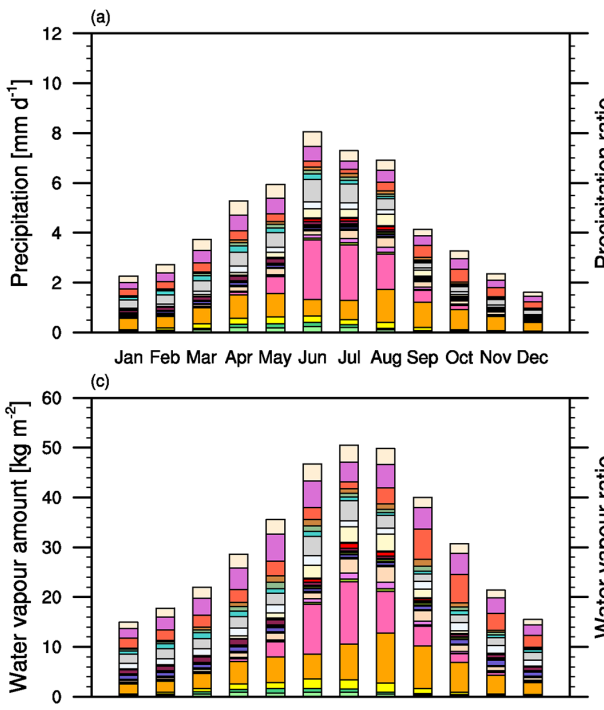

Jan Feb Mar Apr May Jun Jul Aug Sep Oct Nov Dec

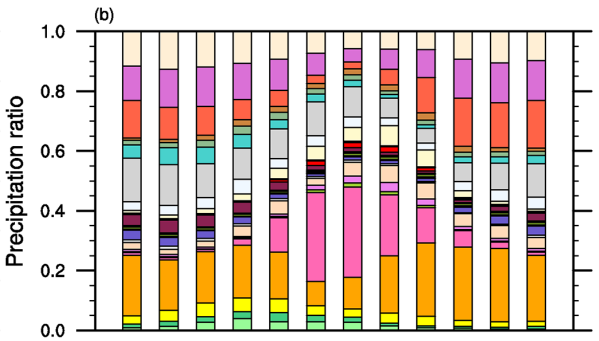

Jan Feb Mar Apr May Jun Jul Aug Sep Oct Nov Dec

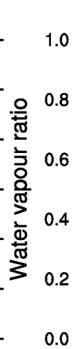

\begin{tabular}{|c|c|c|c|c|c|c|c|c|}
\hline$\square$ 1. BOB & $\square$ & 2. AS & $\square$ & 3. SCS & $\square$ & 4. NWP & $\square$ & $5 . \mathrm{NIO}$ \\
\hline (6.SIO & $\square$ & 7. SP & $\square$ & 8. NEP & $\square$ & 9. SAO & $\square$ & 10. NAO \\
\hline$\square$ 11. ARC & $\square$ & 12. NAM & $\square$ & 13. SAM & $\square$ & 14. AF & 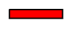 & 15. AUS \\
\hline 16. ANC & $\sqsubset$ & 17. SEA & $\square$ & 18. TP & 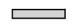 & 19. ICP & 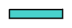 & 20. IND \\
\hline 21. EUP & & 22. NA & 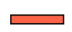 & 23. NEA & $\square$ & 24. YRV & $\square$ & $25 . \mathrm{SCN}$ \\
\hline
\end{tabular}

Figure 6. (a) Monthly averaged evaporative contributions of 25 defined source regions to the precipitation over the YRV. (b) Same as (a), but for the relative contribution to precipitation. (c) Monthly averaged evaporative contributions of 25 defined source regions to the tropospheric total water vapour amount over the YRV. (d) Same as (c), but for the relative contribution to water vapour. Stacked column colours correspond to source region colours in Fig. 1.

sion of this issue is presented in Sect. 3.5. The NWP serves as the dominant oceanic source region for precipitation over the YRV during the whole year except during June and July. The relative contribution is $\sim 8.1-10.6 \%$ in June and July and $15.8-24.6 \%$ in other months. As shown in Fig. 3, there is strong westward water vapour flux over $20-45^{\circ} \mathrm{N}$ for the NWP and south-westward water vapour flux over the tropics of the NWP. However, there is no evident moisture transports from the NWP to EA in the long-term-mean water vapour flux. Following Eq. (S1), the water vapour flux is divided into the stationary and transient components, as shown in Figs. S8-S9. The transient component of the meridional flux brings some of the moisture from south over most of the NWP and the north of the SCS (Fig. S8c), and the transient component of the zonal flux leads to westwards water vapour transport over $20-30^{\circ} \mathrm{N}$ for the NWP (Fig. S9c). Both the transient components indicate that the synoptic disturbances can bring moisture originating from the NWP to the southern and eastern coastal regions of Asia during winter. Evaporation from the NIO shows a clear contribution to precipitation during May to October. In particular, the NIO is the dominant oceanic source region in June and July, with a contribution of $\sim 30 \%$. This is in agreement with the result of a Lagrangian diagnostic method described in Baker et al. (2015) and the re- 

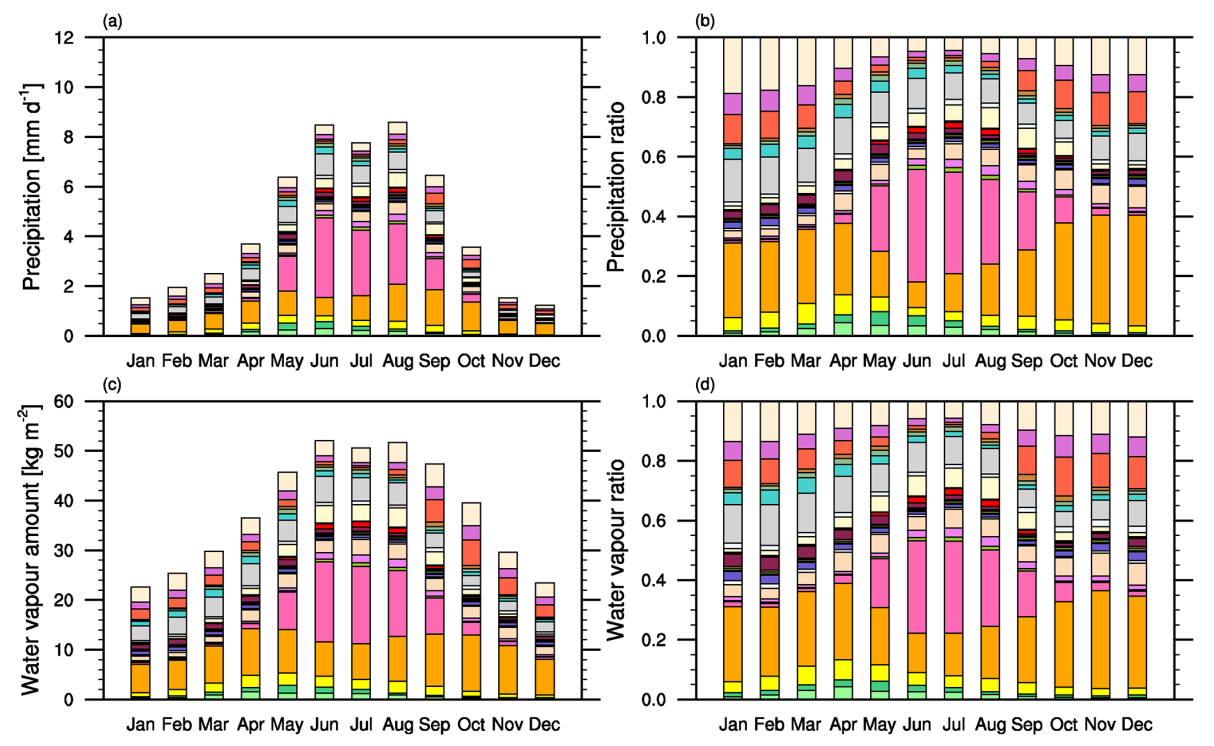

Jan Feb Mar Apr May Jun Jul Aug Sep Oct Nov Dec
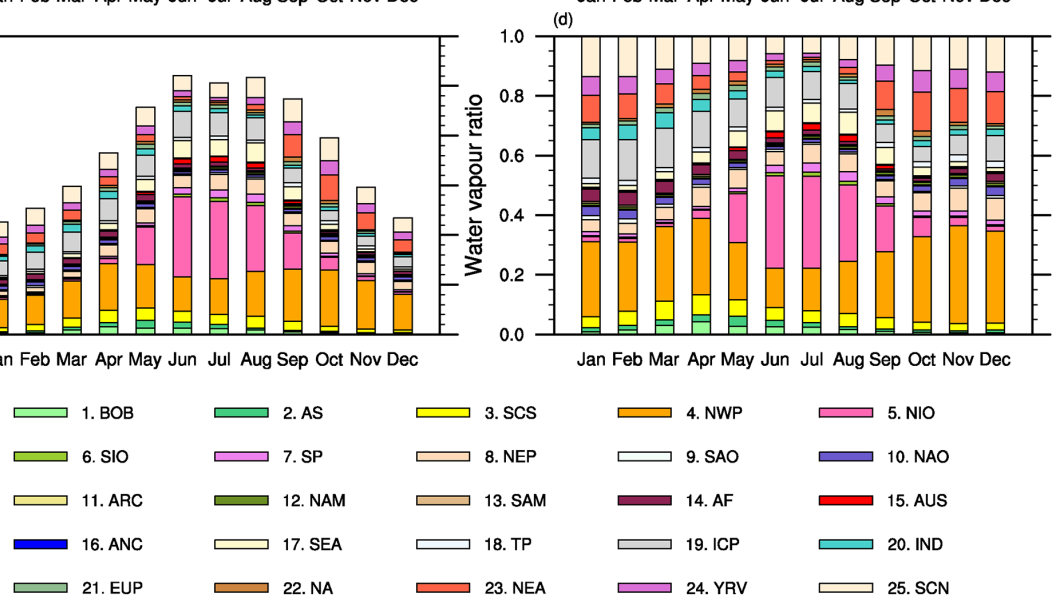

Figure 7. Same as Fig. 6, but for the contributions and relative contributions of 25 source regions to precipitation and tropospheric total water vapour amount over SCN.

sults of sensitivity experiments in Chow et al. (2008). However, in other months, the contribution of the NIO is very small. The contributions from evaporation from the BOB, AS, and NIO are in phase with the EASM, which was also reported by Baker et al. (2015). The ICP is an important terrestrial source region for the YRV precipitation, supplying moisture to $\sim 9.9 \%$ of the annual precipitation. The relative contribution of the ICP from April to September is close to the result of Wei et al. (2012). The contribution of evaporation from the YRV to its precipitation can be regarded as the local recycling ratio, which is lower $(4.5-7.4 \%)$ in summer and higher (9.2-13.4\%) in other seasons. In general, the contribution of evaporation from SCN is comparable to the local contribution of the YRV. The relative contribution from the NEA is higher in autumn-winter and lower in springsummer, which may be associated with the shift of the EA monsoon. Though the individual contributions of evaporation from the YRV or SCN are smaller than those from the NIO in summer, their combined contributions exceed $10 \%$. This implies that evaporation from these two regions is important for precipitation over China. This is contrary to the view expressed in Simmonds et al. (1999) and Qian et al. (2004), but consistent with Wei et al. (2012). Figure $6 \mathrm{c}$ and d show a time series of evaporative contribution from each source region to the tropospheric water vapour amount over the YRV. The overall relative contribution from each source region to the total water vapour amount is similar to the corresponding relative contribution to precipitation shown in Fig. 6a and b.

\subsection{Atmospheric moisture source attribution of precipitation and water vapour over $\mathrm{SCN}$}

Figure $7 \mathrm{a}$ and $\mathrm{b}$ show the contribution of each source region to precipitation over SCN. The NIO is the dominant source region in summer, while the NWP dominates precipitation over SCN during other seasons, which is similar to the situation over the YRV. The contribution from the NIO is $28.4-37.8 \%$ in summer. The contribution from the NWP is $8.7-17.2 \%$ in summer and $\sim 15.3-37.2 \%$ during other seasons. During spring and summer, $\sim 2-4.4 \%$ of precipitation is supplied from the BOB, with smaller contributions during other seasons. The contribution from the AS is similar to that of the BOB. In summer, only $2.7-3.7 \%$ of precipitation originates from the SCS, but the area contributes $\sim 6.7-$ $7 \%$ to the precipitation in early spring (March-April). Similar to precipitation over the YRV, the dominant terrestrial source region for $\mathrm{SCN}$ is the ICP, which contributes $~ 9.8 \%$ to the precipitation. In addition, $\sim 5.6 \%$ of summer precipitation originates from SEA. Compared to precipitation over the YRV, the contribution from the TP is smaller. In addition, the contribution from the YRV is small in summer. The local recycling ratio or percentage contribution of evaporation from SCN is generally 4.3-7.2\% during May to September, 


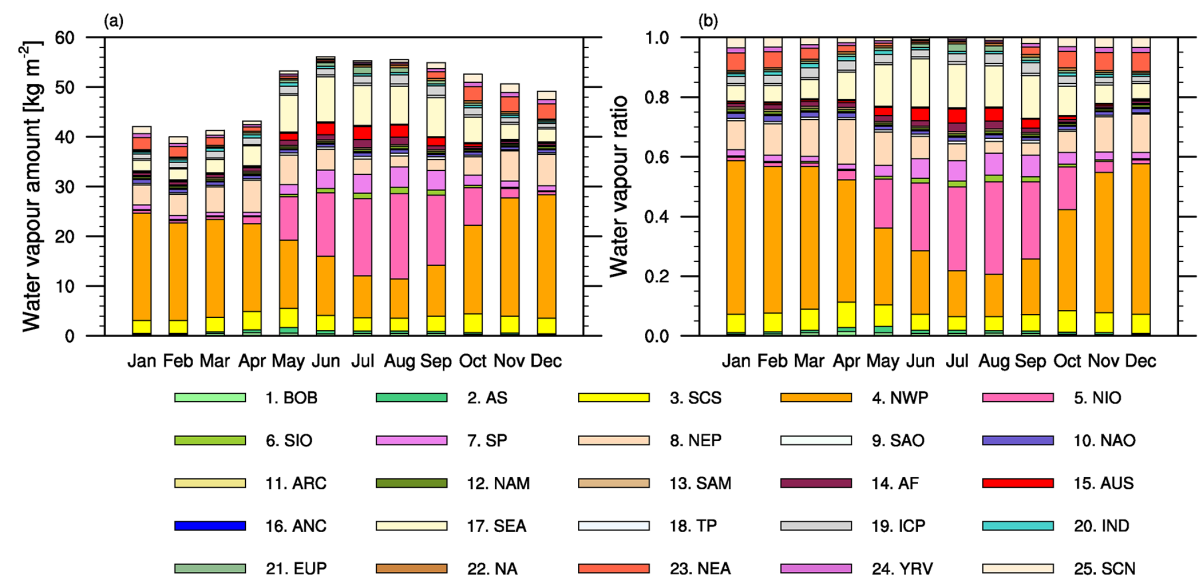

Figure 8. (a) Monthly averaged evolution of evaporative contribution of 25 defined source regions to the tropospheric total water vapour amount over the SCS. (b) Same as (a), but for the relative contribution of water vapour. Stacked column colours correspond to source region colours in Fig. 1.

but larger than $9.3 \%$ during the remaining months. As shown in Fig. 7d, the overall relative contribution of each source region to the water vapour amount is similar to each region's contribution to precipitation over SCN.

\subsection{Atmospheric moisture source attribution of water vapour over the SCS}

Simmonds et al. (1999) and Lau et al. (2002) suggested that interannual variation of summer precipitation over China is associated with water vapour transport over the SCS. However, Chow et al. (2008) suggested that the SCS may act as a water vapour transport pathway where the southwesterly stream of the Indian summer monsoon and the easterly stream of the south-eastern Asian monsoon meet. Previous studies have conducted sensitivity experiments or analysed the water vapour budget to indirectly determine moisture sources for the SCS. In contrast, our AWT method can directly quantify the contribution of each source region to the water vapour amount over the SCS, which is shown in Fig. 8. The local contribution of the SCS is small $(\sim 4.7-$ $5.5 \%$ ) in summer, and the mean contribution in other months is $\sim 6.8 \%$. The contribution of the NIO shows clear seasonal variations: the contribution is high during May to October, but very small during the other months. Similar to the results for water vapour over the YRV and SCN, the NIO is the dominant source region from June to September, with a contribution of $22.7-31 \%$. During this period, the contribution of the NWP is $14.1-21.2 \%$. However, the NWP dominates the water vapour over the SCS in the remaining months, with contributions of 25.7-51.3\%. In addition, the SP and northeastern Pacific (NEP) are also important oceanic source regions, with combined annual contributions of $\sim 11-16.6 \%$. The most important terrestrial moisture source region is the SEA, whose contribution is larger (13.8-16.2\%) in summer and smaller $(\sim 5.3 \%)$ in winter. During late autumn to win- ter, about $5.3-6.3 \%$ of water vapour is supplied from NEA, but its contribution is very small in other seasons. The other land source regions contribute relatively little to the water vapour amount over the SCS.

From the SCS to SCN and further to the YRV (from south to north), surface evaporation from the SCS generally represents a small $(\leq 5.5 \%)$ contribution to the water vapour amount over the three target areas in summer. In contrast, much more water vapour is supplied by evaporation from the NWP and NIO. This confirms the inference proposed by Chow et al. (2008) that the SCS is a water vapour transport pathway where moisture from the NIO and NWP meet in summer.

\section{Conclusions}

In this study, an Eulerian tagged AWT method was implemented in CAM5.1, which provides the capacity to separately trace the behaviour of atmospheric water substances originating from various moisture source regions and to quantify their contributions to atmospheric water over an arbitrary region. Numaguti (1999) pointed out that the weakness of the tagged AWT method is that its results suffer from the performance of the model in reproducing the hydrological cycle. However, a comparison between GPCP and CAM5.1 precipitation shows that CAM5.1 has the capability to represent total precipitation. CAM5.1 also can reproduce water vapour and large-scale circulation reasonably, as compared to AIRS and NCEP data. Using this method, we investigated the contribution of evaporation from land, as well as the contributions from the North Atlantic Ocean, extended northern Indian Ocean, and extended north-western Pacific to precipitation over Eurasia. Our results are similar to those of Numaguti (1999), except that our results indicate a larger contribution from terrestrial source regions, while the three 
oceanic regions show smaller contributions. Different model resolutions and a bias in MERRA surface evaporation are probable causes for the differences between our results and those of Numaguti (1999).

We then investigated the contribution of various source regions to precipitation and water vapour amounts over the YRV and SCN. Our results suggest that the dominant oceanic moisture source region during summer is the NIO (20.5$30.3 \%$ of precipitation over the YRV; $28.4-37.8 \%$ of precipitation over SCN), consistent with Baker et al. (2015) and Chow et al. (2008), whereas during other seasons, the NWP is the dominant source region (15.8-24.6\% of precipitation over the YRV; $15.3-37.1 \%$ of precipitation over SCN), with smaller contributions from the BOB, AS, and SCS. The ICP is an important terrestrial source region, with a mean annual contribution of $\sim 10 \%$. For precipitation over the YRV, the combined contribution of evaporation from the YRV and SCN is non-negligible (exceeding $10 \%$ ), consistent with Wei et al. (2012). For precipitation over SCN, the local recycling ratio is generally $4.3-7.2 \%$ during May to September, and reaches $9.4-18.7 \%$ in other months. The contribution from the YRV is very small in summer. The overall relative contribution of each source region to the water vapour amount is similar to the corresponding contribution to precipitation over the YRV and SCN.

An analysis of water vapour amount over the SCS shows that the NIO is the dominant source region $(22.7-31 \%$ of water vapour) during June to September, while the NWP dominates (25.7-51.3\% of water vapour) in the remaining months. In contrast, the local contribution of the SCS is smaller $(\sim 4.7-5.5 \%)$ in summer. In addition, the SP, NEP, and SEA are also important source regions. Evaporation over the SCS represents a small contribution to water vapour amounts over the SCS, SCN, and the YRV in summer, implying that the SCS acts as a water vapour transport pathway rather than a dominant source region, which confirms the inference of Chow et al. (2008).

At present, the tagged AWT method has only been applied to a few GCMs and regional models, and has generally focused on identifying the moisture distribution over a few regions such as North America (Bosilovich and Schubert, 2002; Bosilovich et al., 2003). We expect that the AWT method will be applied to additional models and used to identify moisture sources over more climate regions, which will improve our understanding of atmospheric moisture transport.

\section{Code availability}

The source code modifications for CAM5.1 are available from the authors. Interested readers should contact Chen Pan (arthur_pc@163.com) or Bin Zhu (binzhu@ nuist.edu.cn).

\section{The Supplement related to this article is available online at doi:10.5194/gmd-10-673-2017-supplement.}

Competing interests. The authors declare that they have no conflict of interest.

Acknowledgements. This work is supported by grants from the National Natural Science Foundation of China (grant no. 91544229), the National Key Research and Development Program of China (2016YFA0602003), and the projects of China Special Fund for Meteorological Research in the Public Interest (GYHY201406001).

Edited by: R. Neale

Reviewed by: two anonymous referees

\section{References}

Baker, A. J., Sodemann, H., Baldini, J. U. L., Breitenbach, S. F. M., Johnson, K. R., van Hunen, J., and Zhang, P.: Seasonality of westerly moisture transport in the East Asian summer monsoon and its implications for interpreting precipitation $\delta^{18} \mathrm{O}$, J. Geophys. Res.-Atmos., 120, 5850-5862, doi:10.1002/2014JD022919, 2015.

Bosilovich, M. G.: On the vertical distribution of local and remote sources of water for precipitation, Meteorol. Atmos. Phys., 80, 31-41, doi:10.1007/s007030200012, 2002.

Bosilovich, M. G. and Schubert, S. D.: Water vapor tracers as diagnostics of the regional hydrologic cycle, J. Hydrometeorol., 3, 149-165, doi:10.1175/15257541(2002)003<0149:WVTADO>2.0.CO;2, 2002.

Bosilovich, M. G., Sud, Y. C., Schubert, S. D., and Walker, G. K.: Numerical simulation of the large-scale North American monsoon water sources, J. Geophys. Res.-Atmos., 108, 8614, doi:10.1029/2002JD003095, 2003.

Bosilovich, M. G., Robertson, F. R., and Chen, J.: Global energy and water budgets in MERRA, J. Climate, 24, 5721-5739, doi:10.1175/2011JCLI4175.1, 2011.

Bretherton, C. S. and Park, S.: A new moist turbulence parameterization in the Community Atmosphere Model, J. Climate, 22, 3422-3448, doi:10.1175/2008JCLI2556.1, 2009.

Bretherton, C. S., McCaa, J. R., and Grenier, H.: A new parameterization for shallow cumulus convection and its application to marine subtropical cloud-topped boundary layers, Part I: Description and 1D results, Mon. Weather Rev., 132, 864-882, doi:10.1175/1520-0493(2004)132<0883:ANPFSC>2.0.CO;2, 2004.

Brubaker, K. L., Entekhabi, D., and Eagleson, P. S.: Estimation of continental precipitation recycling, J. Climate, 6, 1077-1089, doi:10.1175/1520-0442(1993)006<1077:EOCPR>2.0.CO;2, 1993.

Burde, G. I. and Zangvil, A.: The estimation of regional precipitation recycling, Part I: Review of recycling models, J. Climate, 14, 2497-2508, doi:10.1175/15200442(2001)014<2497:TEORPR>2.0.CO;2, 2001. 
Chen, B., Xu, X. D., and Zhao, T.: Main moisture sources affecting lower Yangtze River Basin in boreal summers during 2004-2009, Int. J. Climatol., 33, 1035-1046, doi:10.1002/joc.3495, 2013.

Chow, K. C., Tong, H. W., and Chan, J. C.: Water vapor sources associated with the early summer precipitation over China, Clim. Dynam., 30, 497-517, doi:10.1007/s00382-007-0301-6, 2008.

Dirmeyer, P. A. and Brubaker, K. L.: Contrasting evaporative moisture sources during the drought of 1988 and the flood of 1993, J. Geophys. Res., 104, 19383-19397, doi:10.1029/1999JD900222, 1999.

Drumond, A., Nieto, R., and Gimeno, L.: Sources of moisture for China and their variations during drier and wetter conditions in 2000-2004: a Lagrangian approach, Clim. Res., 5, 215-225, doi:10.3354/cr01043, 2011.

Eltahir, E. A. and Bras, R. L.: Precipitation recycling, Rev. Geophys., 34, 367-378, doi:10.1029/96RG01927, 1996.

Emmons, L. K., Walters, S., Hess, P. G., Lamarque, J.-F., Pfister, G. G., Fillmore, D., Granier, C., Guenther, A., Kinnison, D., Laepple, T., Orlando, J., Tie, X., Tyndall, G., Wiedinmyer, C., Baughcum, S. L., and Kloster, S.: Description and evaluation of the Model for Ozone and Related chemical Tracers, version 4 (MOZART-4), Geosci. Model Dev., 3, 43-67, doi:10.5194/gmd3-43-2010, 2010.

Gettelman, A., Liu, X., Ghan, S. J., Morrison, H., Park, S., Conley, A. J., Klein, S. A., Boyle, J., Mitchell, D. L., and Li, J.-L. F.: Global simulations of ice nucleation and ice supersaturation with an improved cloud scheme in the Community Atmosphere Model, J. Geophys. Res., 115, D18216, doi:10.1029/2009JD013797, 2010.

Gimeno, L., Stohl, A., Trigo, R. M., Dominguez, F., Yoshimura, K., Yu, L., Drumond, A., Durán-Quesada, A. M., and Nieto, R.: Oceanic and terrestrial sources of continental precipitation, Rev. Geophys., 50, RG4003, doi:10.1029/2012RG000389, 2012.

Gustafsson, M., Rayner, D., and Chen, D.: Extreme rainfall events in southern Sweden: where does the moisture come from?, Tellus A, 62, 605-616, doi:10.1111/j.1600-0870.2010.00456.x, 2010.

Held, I. M. and Soden, B. J.: Water vapor feedback and global warming, Annu. Rev. Energy Environ., 25, 441-475, doi:10.1146/annurev.energy.25.1.441, 2000.

Horowitz, L. W., Walters, S., Mauzerall, D. L., Emmons, L. K., Rasch, P. J., Granier, C., Tie, X. X., Lamarque, J.-F., Schultz, M. G., Tyndall, G. S., Orlando, J. J., and Brasseur, G. P.: A global simulation of tropospheric ozone and related tracers: Description and evaluation of MOZART, version 2, J. Geophys. Res., 108, 4784, doi:10.1029/2002JD002853, 2003.

Huffman, G. J. and Bolvin, D. T.: GPCP version 2.2 combined precipitation data set documentation, NASA Goddard Space Flight Center, Mesoscale Atmospheric Processes Laboratory and Science Systems and Applications, Inc., 2011.

Jiménez, C., Prigent, C., Mueller, B., Seneviratne, S. I., McCabe, M. F., Wood, E. F., Rossow, W. B., Balsamo, G., Betts, A. K., Dirmeyer, P. A., Fisher, J. B., Jung, M., Kanamitsu, M., Reichle, R. H., Reichstein, M., Rodell, M., Sheffield, J., Tu, K., and Wang, K.: Global intercomparison of 12 land surface heat flux estimates, J. Geophys. Res., 116, D02102, doi:10.1029/2010JD014545, 2011.

Joussaume, S., Sadourny, R., and Vignal, C.: Origin of precipitating water in a numerical simulation of the July climate, Ocean-Air Inter., 1, 43-56, 1986.
Knoche, H. R. and Kunstmann, H.: Tracking atmospheric water pathways by direct evaporation tagging: A case study for West Africa, J. Geophys. Res.-Atmos., 118, 12345-12358, doi:10.1002/2013JD019976, 2013.

Koster, R., Jouzel, J., Suozzo, R., Russell, G., Broecker, W., Rind, D., and Eagleson, P.: Global sources of local precipitation as determined by the NASA/GISS GCM, Geophys. Res. Lett., 13, 121-124, doi:10.1029/GL013i002p00121, 1986.

Lamarque, J.-F., Emmons, L. K., Hess, P. G., Kinnison, D. E., Tilmes, S., Vitt, F., Heald, C. L., Holland, E. A., Lauritzen, P. H., Neu, J., Orlando, J. J., Rasch, P. J., and Tyndall, G. K.: CAM-chem: description and evaluation of interactive atmospheric chemistry in the Community Earth System Model, Geosci. Model Dev., 5, 369-411, doi:10.5194/gmd-5-369-2012, 2012.

Lau, K. M., Li, X., and Wu, H. T.: Evolution of the large scale circulation, cloud structure and regional water cycle associated with the South China Sea monsoon during May-June, 1998, J. Meteorol. Soc. Jpn., 80, 1129-1147, doi:10.2151/jmsj.80.1129, 2002.

Lin, Y. L., Farley, R. D., and Orville, H. D.: Bulk parameterization of the snow field in a cloud model, $\mathrm{J}$. Clim. Appl. Meteorol., 22, 1065-1092, doi:10.1175/15200450(1983)022<1065:BPOTSF>2.0.CO;2, 1983.

Morrison, H. and Gettelman, A.: A new two-moment bulk stratiform cloud microphysics scheme in the Community Atmosphere Model, version 3 (CAM3), Part I: Description and numerical tests, J. Climate, 21, 3642-3659, doi:10.1175/2008JCLI2105.1, 2008.

Morrison, H. and Pinto, J. O.: Mesoscale modeling of springtime Arctic mixed-phase stratiform clouds using a new twomoment bulk microphysics scheme, J. Atmos. Sci., 62, 36833704, doi:10.1175/JAS3564.1, 2005.

Neale, R. B., Chen, C.-C., Gettelman, A., Lauritzen, P. H., Park, S., Williamson, D. L., Conley, A. J., Garcia, R., Kinnison, D., Lamarque, J.-F., Marsh, D., Mills, M., Smith, A. K., Tilmes, S., Vitt, F., Morrison, H., Gameron-Smith, P., Collins, W. D., Iacono, M. J., Easter, R. C., Ghan, S. J., Liu, X., Rasch, P. J., and Taylor, M. A.: Description of the NCAR Community Atmosphere Model (CAM5), NCAR Technical Note NCAR/TN-486+STR, 275 pp., 2012.

Numaguti, A.: Origin and recycling processes of precipitating water over the Eurasian continent: Experiments using an atmospheric general circulation model, J. Geophys. Res., 104, 1957-1972, doi:10.1029/1998JD200026, 1999.

Park, S. and Bretherton, C. S.: The University of Washington shallow convection and moist turbulence schemes and their impact on climate simulations with the Community Atmosphere Model, J. Climate, 22, 3449-3469, doi:10.1175/2008JCLI2557.1, 2009.

Park, S., Bretherton, C. S., and Rasch, P. J.: Integrating cloud processes in the Community Atmosphere Model, version 5, J. Climate, 27, 6821-6856, doi:10.1175/JCLI-D-14-00087.1, 2014.

Qian, J. H., Tao, W. K., and Lau, K. M.: Mechanisms for Torrential Rain Associated with the Mei-Yu Development during SCSMEX 1998, Mon. Weather Rev., 132, 3-27, doi:10.1175/15200493(2004)132<0003:MFTRAW>2.0.CO;2, 2004.

Rasch, P. J., Coleman, D. B., Mahowald, N., and Williamson, D. L.: Characteristics of Atmospheric Transport Using Three Numerical Formulations for Atmospheric Dynamics 
in a Single GCM Framework, J. Climate, 19, 2243-2266, doi:10.1175/JCLI3763.1, 2006.

Rasch, P. J., Mahowald, N. M., and Eaton, B. E.: Representations of transport, convection, and the hydrologic cycle in chemical transport models: Implications for the modeling of shortlived and soluble species, J. Geophys. Res., 102, 28127-28138, doi:10.1029/97JD02087, 1997.

Raymond, D. J. and Blyth, A. M.: A stochastic mixing model for nonprecipitating cumulus clouds, J. Atmos. Sci., 43, 2708-2718, doi:10.1175/1520-0469(1986)043<2708:ASMMFN>2.0.CO;2, 1986.

Raymond, D. J. and Blyth, A. M.: Extension of the stochastic mixing model to cumulonimbus clouds, J. Atmos. Sci., 49, 1968-1983, doi:10.1175/15200469(1992)049<1968:EOTSMM>2.0.CO;2, 1992.

Reisner, J., Rasmussen, R. M., and Bruintjes, R. T.: Explicit forecasting of supercooled liquid water in winter storms using the MM5 mesoscale model, Q. J. Roy. Meteor. Soc., 124, 10711107, doi:10.1002/qj.49712454804, 1998.

Richter, J. H. and Rasch, P. J.: Effects of convective momentum transport on the atmospheric circulation in the community atmosphere model, version 3, J. Climate, 21, 1487-1499, doi:10.1175/2007JCLI1789.1, 2008.

Rienecker, M. M., Suarez, M. J., Gelaro, R., Todling, R., Bacmeister, J., Liu, E., Bosilovich, M. G., Schubert, S. D., Takacs, L., Kim, G.-K., Bloom, S., Chen, J., Collins, D., Conaty, A., da Silva, A., Gu, W., Joiner, J., Koster, R. D., Lucchesi, R., Molod, A., Owens, T., Pawson, S., Pegion, P., Redder, C. R., Reichle, R., Robertson, F. R., Ruddick, A. G., Sienkiewicz, M., and Woollen, J.: MERRA: NASA's Modern-Era Retrospective analysis for Research and Applications, J. Climate, 24, 3624-3648, doi:10.1175/JCLI-D-11-00015.1, 2011.

Savenije, H. H. G.: New definitions for moisture recycling and the relationship with land-use changes in the Sahel, J. Hydrol., 167, 57-78, doi:10.1016/0022-1694(94)02632-L, 1995.

Simmonds, I., Bi, D. and Hope, P.: Atmospheric Water Vapor Flux and Its Association with Rainfall over China in Summer, J. Climate, 12, 1353-1367, doi:10.1175/15200442(1999)012<1353:AWVFAI>2.0.CO;2, 1999.

Sodemann, H. and Zubler, E.: Seasonal and interannual variability of the moisture sources for Alpine precipitation during 19952002, Int. J. Climatol., 30, 947-961, doi:10.1002/joc.1932, 2010.

Sodemann, H., Schwierz, C., and Wernli, H.: Interannual variability of Greenland winter precipitation sources: Lagrangian moisture diagnostic and North Atlantic Oscillation influence, J. Geophys. Res., 113, D03107, doi:10.1029/2007JD008503, 2008.
Sodemann, H., Wernli, H., and Schwierz, C.: Sources of water vapour contributing to the Elbe flood in August 2002 - A tagging study in a mesoscale model, Q. J. Roy. Meteorol. Soc., 135, 205-223, doi:10.1002/qj.374, 2009.

Stohl, A. and James, P.: A Lagrangian analysis of the atmospheric branch of the global water cycle, Part I: Method description, validation, and demonstration for the August 2002 flooding in central Europe, J. Hydrometeorol., 5, 656-678, doi:10.1175/15257541(2004)005<0656:ALAOTA>2.0.CO;2, 2004.

Stohl, A., Forster, C., and Sodemann, H.: Remote sources of water vapor forming precipitation on the Norwegian west coast at $60^{\circ} \mathrm{N}-$ a tale of hurricanes and an atmospheric river, J. Geophys. Res., 113, D05102, doi:10.1029/2007JD009006, 2008.

Sundqvist, H.: Parameterization of condensation and associated clouds in models for weather prediction and general circulation simulation, Physically-based modelling and simulation of climate and climatic change, Springer Netherlands, 433-461, 1998.

Thompson, G., Rasmussen, R. M., and Manning, K.: Explicit forecasts of winter precipitation using an improved bulk microphysics scheme, Part I: Description and sensitivity analysis, Mon. Weather Rev., 132, 519-542, doi:10.1175/15200493(2004)132<0519:EFOWPU>2.0.CO;2, 2004.

Trenberth, K. E.: Atmospheric moisture recycling: Role of advection and local evaporation, J. Climate, 12, 1368-1381, doi:10.1175/1520-0442(1999)012<1368:AMRROA>2.0.CO;2, 1999.

Wei, J., Dirmeyer, P. A., Bosilovich, M. G., and Wu, R.: Water vapor sources for Yangtze River Valley rainfall: Climatology, variability, and implications for rainfall forecasting, J. Geophys. Res.Atmos., 117, D05126, doi:10.1029/2011JD016902, 2012.

Xu, X. D., Shi, X. Y., Wang, Y. Q., Peng, S. Q., and Shi, X. H.: Data analysis and numerical simulation of moisture source and transport associated with summer precipitation in the Yangtze River Valley over China, Meteorol. Atmos. Phys., 100, 217-231, doi:10.1007/s00703-008-0305-8, 2008.

Zhang, G. J. and McFarlane, N. A.: Sensitivity of climate simulations to the parameterization of cumulus convection in the Canadian Climate Centre general circulation model, Atmos. Ocean, 33, 407-446, doi:10.1080/07055900.1995.9649539, 1995.

Zhang, M., Lin, W., Bretherton, C., Hack, J., and Rasch, P. J.: A modified formulation of fractional stratiform condensation rate in the NCAR Community Atmospheric Model (CAM2), J. Geophys. Res., 108, 4035, doi:10.1029/2002JD002523, 2003. 